

\section{Sumário}

Dossiê Temático: Direito Internacional Econômico.........................................................1

EDITORIAL:

Resultados da III Conferência Bienal da Red DEI ................................................. 3

Michelle Ratton Sanchez-Badin (em nome da Diretoria da Red DEI), Fabio Costa Morosini e Lucas da Silva Tasquetto (em nome dos organizadores da III Conferência da Red DEI)

Direito Internacional Econômico no Brasil: QUem Somos E o QUE faZemos? EvidênCIas EMPÍRICAS DE 1994 A 2014

Michelle Ratton Sanchez Badin, Fabio Costa Morosini e Inaê Siqueira de Oliveira

UM ESPAÇO PARA PENSAR EM ALTERNATIVAS? A ACADEMIA LATINO-AMERICANA DE DIREITO INTERNACIONAL ECONÔMICO FRENTE À ORDEM ECONÔMICA GLOBAL

Nicolás Marcelo Perrone

Grupo de alto Nível Brasil - Urugua (GAN): um Novo paradigma para a INTEgraÇão PRODUTIVA NO MERCOSUL

Alebe Linhares Mesquita e Vivian Daniele Rocha Gabriel

O COMÉRCIO de SERVIÇOS ENTRE Brasil E URUGUAI: LiberalizaÇÃo, DESAFIOS E PERSPECTIVAS DO SETOR DE TECNOLOGIA DA INFORMAÇÃO E COMUNICAÇÃO (TIC) E SOFTWARES

Vivian Daniele Rocha Gabriel e Alebe Linhares Mesquita

Core Labor Standards No Regime de PREFERÊNCIAS TARIFÁrias No MERCOSUL: A NeCESSIDADE DE HUMANIZAÇÃO DO COMÉRCIO INTERNACIONAL

Martinho Martins Botelho e Marco Antônio César Villatore

ACordo TRIMS: FleXibilizaÇão ou Não? Política de CONTEÚdo loCal, PROCESSO PROdUTIVO BÁSICO (PPB) E OS DESAFIOS PARA A INDÚSTRIA BRASILEIRA E A INTEGRAÇÃo LATINO-AMERICANA 100

Natália Figueiredo 
ESTUDIOS DE CASO DE RECHAZOS EN FRONTERA DE EXPORTACIONES ALIMENTARIAS LATINOAMERICANAS POR MOTIVOS RELACIONADOS CON MEDIDAS TÉCNICAS NO ARANCELARIAS.

Sofía Boza, Juan Rozas e Rodolfo Rivers

América do Sul em face dos tratados bilaterais de inVESTimento: RUMO aO RETORNo do EsTADO NA SOLUÇão DE CONTROvÉRSIAS? 133 Magdalena Bas

FutURo DE LOS SISTEMAS NACIONALES DE CIENCIA TECNOLOGÍA E INNOVACIÓN EN LA AGENDA ECONÓMICA DE AMÉRICA LATINA: DEFINIENDO CAMBIOS REGULATORIOS O PROTEGIENDO INVERSIONES 146

Rodrigo Corredor

EL PAPEL DE LAS INSTITUCIONES DE CONTROL FINANCIERO SOBRE LOS DERECHOS HUMANOS EN EL CONTEXTO LATINOAMERICANO 157 Jose Miguel Camacho Castro

CONVERGENCIA REgUlATORIA EN LA ALIANZA DEL PACÍFICO: UN CAPÍTULO INCONCLUSO 170 Rodrigo Polanco Lazo

O CONSTITUCIONALISMO E A COMUNITARIZAÇÃO NO DIREITO INTERNACIONAL: POSSIBILIDADES PARA O COMÉRCIO INTERNACIONAL?

Camilla Capucio

ESCASSEZ HÍDRICA E DIREITO INTERNACIONAL ECONÔMICO: O BRASIL COMO PROTAGONISTA NA TRANSFERÊNCIA DE ÁGUA PARA REGIÕES ÁRIDAS

Douglas de Castro

A Segurança energética como base para maior integração na América Do Sul: à espera DE UM TRATADO MULTILATERAL

Matheus Bassani

Outros Artigos. 246

As PRÁtICAS RESTRITIVAS DA CONCORRÊNCIA NO MERCADO DE CONTRATAÇÃo PÚBLICA EUROPEU .. 248 Alice Rocha da Silva e Ruth M. P. Santos 
Do TRANSNACIONAL PARA O NACIONAL: IOSCO, O MERCADO DE VALORES MOBILIÁRIOS BRASILEIRO E ACCOUNTABILITY

Salem Nasser, Nora Rachman e Viviane Muller Prado

MigRaÇÃo de TRABALHADORES INTELECTUAIS BRASILEIROS PARA O MERCADO INTERNACIONAL: IDENTIFICAÇÃO DE ATOS DE ALICIAMENTO DE EMPREGADOS E MECANISMOS LEGAIS PARA IMPEDIR A APROPRIAÇÃo TECNOLÓGICA E CONCORRÊNCIA DESLEAL ..........................................285 José Carlos Vaz e Dias e João Marcelo Sant'Anna da Costa

THE EASIER WAY TO HAVE "BETTER LAW"? THE MOST-SIGNIFICANT-RELATIONSHIP DOCTRINE AS THE FALLBACK CONFLICT-OF-LAW RULE IN THE PEOPLE'S REPUBLIC OF CHINA

Chi Chung

REFLEXOS JURÍDiCOS DA GOVERNANÇA GLOBAL SUBNACIONAL: A PARADIPLOMACIA E O DIREITO INTERNACIONAL: DESAFIO OU ACOMODAÇÃO 320

Valéria Cristina Farias e Fernando Rei

Matrizes Políticas da JUSTiÇA PENAL INTERNACIONAL. 341 Francisco Rezek

RESPONSABILIDAD INTERNACIONAL DEL ESTADO FRENTE A LUCHA CONTRA LA DISCRIMINACIÓN RACIAL Y ÉTNICA EN ESPAÑA. 348

Edilney Tomé da Mata e Eduardo Biacchi Gomes Correio

The Peace Process in Sierra Leone: an analysis on marriages between culture and CRIME

Gustavo Bussmann Ferreira

Funcionalização e expansão do Direito Penal: o Direito Penal negocial ...............376 Antonio Henrique Graciano Suxberger e Dermeval Farias Gomes Filho

Proteção Internacional do Consumidor e Cooperação Interjurisdicional .396 Héctor Valverde Santana e Sophia Martini Vial

The land rights of indigenous and traditional peoples in Brazil and Australia.... 418 Márcia Dieguez Leuzinger e Kylie Lyngard 
The reception of European ideas in Latin America: the issue of the German sources in Tobias Barreto, A Prominent nineteenth CENTURy BraZilian legal scholar........439 Arnaldo Sampaio de Moraes Godoy

Normas Editoriais ..................................................................................... 461 


\title{
Direito Internacional Econômico no Brasil: quem somos e o que fazemos? Evidências empíricas de 1994 a 2014*
}

\author{
International Economic Law in Brazil: who \\ are we and what we do? Empirical evidence \\ from 1994 to 2014
}

\author{
Michelle Ratton Sanchez Badin ** \\ Fabio Costa Morosini *** \\ Inaê Siqueira de Oliveira ****
}

* Recebido em 16/03/2016

Aprovado em 02/05/2016

** Professora associada e coordenadora do Núcleo de Direito Global e Desenvolvimento na Escola de Direito da Fundação Getulio Vargas (FGV Direito SP). Bacharel e Doutora pela Faculdade de Direito da Universidade de São Paulo. Pós-doutorado na New York University, Global Hauser Law Program. Foi pesquisadora visitante no Graduate Institute of International Studies and Development e na University of California, Irvine, School of Law. Fundadora e membro do conselho executivo da Society of International Economic Law (2008-2012) e atual membro do diretoria executiva da Red Latinoamericana de Derecho Economico Internacional (2014-...). Bolsista FAPESP em Apoio à Pesquisa (2014/25776-4). E-mail: Michelle. Sanchez@fgv.br

*** Professor da Faculdade de Direito da Universidade Federal do Rio Grande do Sul (UFRGS), onde coordena o Centro para Direito, Globalização e Desenvolvimento. Fellow da Organização Mundial do Comércio (2009-2010). Ph.D. em Direito Internacional pela University of Texas at Austin (2007), mestre em Master of Laws pela University of Texas at Austin (2001) e mestre em D.E.S.S. Droit et Globalisation Économique pela Université de Paris I (Panthéon-Sorbonne) e Institut d'Édutes Politiques de Paris (Sciences Po) (2004). Bolsista Produtividade em Pesquisa Nível 2 do CNPq. E-mail: Fabio.Morosini@ufrgs.br.

**** Graduanda em Ciências Jurídicas e Sociais na Universidade Federal do Rio Grande do Sul (UFRGS), $4^{\circ}$ ano. Foi Bolsista no Programa de Iniciação Científica da FGV Direito SP no período 2013/2014. Desde agosto de 2014, é Bolsista no Programa de Iniciação Científica CNPq-UFRGS. E-mail: Inae.Oliveira@ufrgs.br.

\section{Resumo}

O campo do Direito Internacional Econômico (DIE) é recente no Brasil tanto como linha de pesquisa quanto como tópico disciplinar para ensino nas Faculdades de Direito. Considerando-se que o Brasil possui mais de mil Faculdades de Direito registradas no Ministério da Educação, o artigo se propõe a analisar o perfil da pesquisa e do ensino em Direito Internacional Econômico no país. Apresenta-se um mapeamento (i) do perfil do pesquisador em DIE no Brasil, (ii) do perfil da pesquisa, nisso compreendido como os pesquisadores têm desenvolvido suas pesquisas neste campo, quais os temas eleitos e as formas de produção e (iii) do perfil do ensino, nisso compreendido quais os temas privilegiados nos cursos desses pesquisadores e seus espaços em suas instituições de ensino. O referido mapeamento foi realizado a partir das informações disponibilizadas nos currículos dos pesquisadores brasileiros (CNPQ/Lattes). O que se pretende com este trabalho é uma aproximação da realidade do Direito Internacional Econômico nas faculdades brasileiras e, sobretudo, uma apreensão mais apurada sobre o que a academia brasileira compreende por Direito Internacional Econômico e sobre como o campo é explorado na produção acadêmica.

Palavras-chave: Direito Internacional Econômico. Brasil. Empírico. Plataforma Lattes.

\section{Abstract}

The International Economic Law field is recent in Brazil not only as a research topic, but also as a course taught at Law Schools. Given that Brazil has more than a thousand Law Schools registered at the Ministry of Education database, this article aims at analyzing what is the profile of International Economic Law that is taught and researched in Brazil. We collected empirical evidence on (i) the profile of IEL scholars, (ii) the profile of the research they conduct, such as the most-common topics and how they vary over time, (ii) the profile of IEL courses, that is to say which are the most- 
-common topics among the courses offered by the scholars and how much space do IEL-related topics receive in Brazilian Law schools. This research was performed based on public information available at the National Counsel of Technological and Scientific Development's Lattes database (CNPQ/Lattes). We hope to provide an overview into the reality of International Economic Law in Brazilian Law Schools, a clearer notion of how the academic community in Brazil defines IEL and how the field is explored scholarly.

Keywords: International Economic Law. Brasil. Empirical evidence. Lattes database.

\section{Introdução: Direito Internacional ECONÔMICO ENQUANTO CAMPO E O SEU MAPEAMENTO EMPÍRICO}

A referência ao Direito Internacional Econômico (DIE) enquanto campo de estudos específico ${ }^{1}$ é relativamente recente, no mundo e também no Brasil. Com base nessa constatação, não são poucos os estudos que procuram delimitar esse campo a partir de seu objeto, de seus princípios ou de suas fontes. ${ }^{2}$ Há, ainda, estudos

1 Aplicamos aqui a ideia de "campo" com o objetivo de deixar a definição aberta para estudos que se vinculam a esta concepção de DIE ao analisar relações econômicas e as regulamentações que sobre elas incidam, com impactos na vida social. Esta é concepção que tem orientado as produções com um enfoque sociológico sobre o Direito Internacional Econômico. Essa abordagem é bastante exemplificada nos estudos organizados por PERRY-KESSARIS, A. (Ed.) Socio-legal approaches to international economic law: text, context, subtext. New York: Routledge, 2013.

2 Circunscrever o campo do Direito Internacional Econômico tem sido uma tarefa cada vez mais ambivalente - ainda que sua definição nunca tenha sido muito clara. CARREAU, D.; FLORY, T.; JULLIARD, P. Droit internacional économique. Paris: Persée, 1990. p. 2-3 apresentaram uma tentativa de definição do DIE, a partir do método tradicional de "fontes": stricto sensu, compreendendo, única e isoladamente, as regulamentações relativas às relações entre os Estados (públicas) face ao externo; e lato sensu, em que compreenderia toda e qualquer forma de regulamentação das relações econômicas, públicas e privadas. Como um marco para as novas pesquisas na área que tratam da dimensão internacional, mas também das questões transnacionais, aproximando o direito doméstico do foco de interesse das perguntas relevantes ao campo do DIE, ORTINO, F.; ORTINO, M. Law on the global economy: in a need for a new methodological approach? In: PICKET, C; BUNN, I; WARNER, D. International economic law: the state and future of the discipline. Oxford: Hart Publishing, 2008. p. 89-106. complexificaram esta definição ao proporem a definição do DIE como resultado (i) de sua associação ao direito internacional, considerando assim as regras que regem as relações econômicas dos sujeitos de direito internacional que possuem pretensões de, com base em alguma delimitação, configurar o campo como nova disciplina ou subdisciplina ou, apenas, deixá-lo como campo. Nossa proposta neste artigo não tem pretensões normativas, que poderiam levar a análises mais dogmáticas ou doutrinárias sobre esse campo. É, sobretudo, um estudo com pretensões descritivas, no qual o uso de técnicas empíricas de pesquisa foi essencial para a formação dos resultados abaixo apresentados. A opção por essa abordagem considera que, por ser um campo novo e, ainda, em disputa, é importante descrever como, no Brasil, os pesquisadores o identificam e delimitam o espaço de suas pesquisas e de ensino sob a epígrafe "Direito Internacional Econômico".

Para tanto, definiu-se como "campo de análise" a Plataforma Lattes ${ }^{3}$, que registra o currículo público de

(definição a partir da origem ou das "fontes" de direito) e (ii) de sua associação ao direito da economia, que considera o estudo de regras que regulamentam atores econômicos e atividades que transpassam fronteiras, ou produzem impactos para além das fronteiras de um único sistema jurídico e econômico e, em razão disso, operam no, ou impactam o, sistema econômico global (definição a partir do objeto). Outros exemplos de tentativas de definição podem ser obtidos em: CHARNOVITZ, S. What is international economic law? Journal of International Economic Law, v. 14, n. 1, p. 3-22, 2014; HERDEGEN, M. Principles of international economic law. Oxford: Oxford University Press, 2013. p. 493; HUDEC, R. International economic law: the political theatre dimension. University of Pennsylvania Journal of International Economic Law, v. 17, n. 1, p. 9-15, 1996; JACKSON, J. H. International economic law: reflections on the "boilerroom" of international relations. American University Journal of International Law and Policy, v. 10, n. 2, p. 595-606, 1994; PETERSMANN, E. U. International economic theory and international economic law: on the tasks of a legal theory of international economic order. In: MAC DONALD, R.; JOHNSTON, D. The structure and process of international law: essays in legal philosophy, doctrine and theory. Leiden: Brill, 1986. p. 227-262; REITZ, Curtis R. International economic law. University of Pennsylvania Journal of International Economic Law, v. 17, n. 1, p. 29-32, 1994; SCHWARZENBERGER, G. The principles and standards of international economic law. Brill: Leiden, 1966. (Collected Courses of the Hague Academy of International Law, v. 117); TRACHTMAN, Joel P. The international economic law revolution. Journal of International Law, v. 17, n. 1, p. 33-61, 1996; VAGTS, Detlev F. International economic law and the American Journal of International Law. American Journal of International Law, v. 100, n. 4, p. 769-782, Oct. 2006; ZAMORA, S. International economic law. University of Pennsylvania Journal of International Economic Law, v. 17, p. 63-67, 1996.

3 Conforme apresentação oficial pelo Conselho Nacional de Desenvolvimento Científico e Tecnológico (CNPq): "A Plataforma Lattes representa a experiência do CNPq na integração de bases de dados de Currículos, de Grupos de pesquisa e de Instituições em um único Sistema de Informações. [...] O Currículo Lattes se tornou um padrão nacional no registro da vida pregressa e atual dos estudantes e pesquisadores do país, e é hoje adotado pela maioria das instituições de fomento, universidades e institutos de pesquisa do País. Por sua riqueza de informações e sua crescente confiabilidade e abrangência, se tornou elemento indispensável e compulsório à 
pesquisadores no Brasil. A "população" analisada foi delimitada pelo uso das expressões "Direito Internacional Econômico" e/ou "Direito Econômico Internacional" nos currículos registrados na Plataforma Lattes ${ }^{5}$, do que decorre que o primeiro e principal critério de delimitação da população foi a autodeclaração dos próprios pesquisadores. Em relação a esse critério, conjugaram-se os de i) doutorado como titulação mínima e ii) última atualização do currículo há no mínimo três anos (ou seja, em 2012). Do total de 115 currículos $^{6}$ relevantes para esta pesquisa, dez não estavam atualizados desde 2012 e foram, por esse motivo, excluídos ${ }^{7}$ Em síntese, 105 currículos compuseram a população final analisada neste artigo, sendo que se estabeleceu os últimos vinte e um anos - 1994 a 2014 - como delimitação temporal da análise da produção acadêmica daquela população.

análise de mérito e competência dos pleitos de financiamentos na área de ciência e tecnologia." Informação disponível em: <http:/ / lattes.cnpq.br/>. Acesso em: 10 set. 2015.

4 Aplica-se aqui o conceito de população de Quivy: “À totalidade destes elementos, ou das 'unidades' constitutivas do conjunto considerado, chama-se 'população', podendo este termos designar tanto um conjunto de pessoas como de organizações ou de objectos de qualquer natureza" QUIVY, R.; CAMPENHOUDT, L. V. Manual de investigação em ciências sociais. 6. ed. Lisboa: Gradiva Publicações, 2013. p. 159.

5 O emprego intercambiado das expressões "Direito Internacional Econômico" ou "Direito Econômico Internacional" evidencia o processo de formação e delimitação em progresso do campo. Dos 115 currículos identificados, 84 aplicaram a expressão "Direito Internacional Econômico", 21 "Direito Econômico Internacional" e 10 aplicam ambas as expressões. Há tentativas na literatura em distinguir estes dois campos ORTINO, F.; ORTINO, M. Law on the global economy: in a need for a new methodological approach? In: PICKET, C; BUNN, I; WARNER, D. International economic law: the state and future of the discipline. Oxford: Hart Publishing, 2008. p. 89-106, contudo, conforme ficará mais claro na apresentação dos dados, observamos nesta coleta de dados que, no caso dos pesquisadores brasileiros, estas expressões parecem ser utilizadas indistintamente.

6 A título de curiosidade sobre a extensão dessa população no cenário da pesquisa e do ensino de Direito no Brasil, a Plataforma Lattes registrava, até 31 janeiro de 2016, o total de 2.912 doutores com vínculo em faculdades de Direito, de um total de 3.098.215 currículos registrados na Plataforma, das mais diversas áreas. Informações disponíveis em: <estatístico.cnpq.br/painelLattes>. Acesso em: 12 fev. 2016.

7 Aplicamos o critério de três anos considerando a temporalidade das avaliações das IES feitas pelos órgãos do sistema de educação do governo federal no Brasil, em especial da "Avaliação do Sistema Nacional de Pós-Graduação" realizada pela CAPES. Essa Avaliação é trienal, foi iniciada em 1998 e a mais recente ocorreu em 2013. Ela abrange os programas de pós-graduação de todas as áreas do conhecimento. A página da área do Direito, onde está disponível o Relatório da Avaliação Trienal 2013, pode ser consultado em: <http://www.capes.gov.br/component/content/article/44avaliacao/4663-direito>. Acesso em: set. 2015.
Os dados dos 105 currículos selecionados foram registrados e as seguintes codificações serviram como instrumento de observação do perfil do pesquisador e do seu trabalho de ensino e pesquisa: i) gênero, ii) nacionalidade, iii) formação acadêmica, iv) atuação profissional, v) atividades de ensino e cursos ministrados, vi) projetos de pesquisa, vii) publicações em periódicos, viii) publicações em livros, coletâneas e capítulos de livros; $i x$ ) teses e dissertações orientadas e $x$ ) outras atividades declaradas pelo pesquisador. As codificações de v) a $x$ ) consideraram a atuação relacionada ao campo do DIE.Com base nos dados levantados, - os quais estão em base de dados disponível para consulta, mediante solicitação -, fizemos alguns mapeamentos e algumas inferências ${ }^{8}$, pontuando quando estas acontecem. A sistematização de alguns dados será apresentada, de forma quantitativa, com o objetivo de auxiliar na contextualização dos dados agregados. O que se pretende com este trabalho é uma aproximação à realidade do Direito Internacional Econômico nas faculdades de direito brasileiras e, sobretudo, uma apreensão mais apurada sobre o que a academia brasileira compreende por Direito Internacional Econômico e sobre como o campo é explorado na produção acadêmica. É, portanto, ainda uma análise formal, a partir dos dados coletados. A pesquisa abre, contudo, um espaço para avanços qualitativos futuros sobre o quadro apresentado.

O artigo é apresentado em três seções e uma breve conclusão. Na primeira seção, apresentamos os resultados do perfil da população analisada; na segunda, o perfil do ensino em DIE, nisso compreendido quais os temas privilegiados nos cursos dos pesquisadores e seus espaços em suas instituições de ensino; e, na terceira, o perfil de pesquisa em DIE, nisso compreendido como os pesquisadores têm desenvolvido suas pesquisas nesse campo, quais os temas eleitos e as formas de produção. Na sequência, apresentamos algumas notas finais.

O perfil da população: quem são os pesquisadores brasileiros em Direito Internacional Econômico? Com base no levantamento dos currículos dos pesquisadores na Plataforma Lattes, para apresentarmos o perfil desta população selecionamos i) características demográficas,

8 Vale explicitar que "inferência" é apresentada nas técnicas de pesquisa empírica como uma interpretação controlada BARDIN, L. Análise de conteúdo. Tradução Luís Antero Reto, Augusto Pinheiro. São Paulo: Edições 70, 2011. p. 165. Isso significa que a coleta de dados e sua sistematização auxiliam na análise do pesquisador, para avançar com graus de objetividade e exercícios de generalização. 
nisso incluso nacionalidade, gênero, ano9 e local de obtenção do título de doutorado, a relação entre espaços de formação acadêmica e de atuação profissional acadêmica, e estágio na carreira acadêmica em 2015; e ii) a dedicação à pesquisa e ao ensino, quanto ao regime de trabalho (na academia).

\section{Características demográficas}

Sobre a nacionalidade, identificamos que a quase totalidade de pesquisadores em DIE Brasil são brasileiros (98,1\%), os dois pesquisadores estrangeiros são latino-americanos, de origem colombiana. Sobre a distribuição de gênero, observamos que a maioria dos pesquisadores em DIE, no Brasil, são homens $(71,4 \%)^{10}$.

Da totalidade da população selecionada, a maioria $(74,3 \%)$ obteve sua formação de doutorado no Brasil, enquanto um quarto $(25,7 \%)$ obteve sua formação de doutorado no exterior. A maior parte da população também registra uma vida como pesquisador doutor recente: $77,14 \%$ obtiveram o título de doutor nos últimos quinze anos - i.e., a partir do ano 2000.

Quando contrastamos o ano de obtenção do doutorado com a instituição e sua localização, observamos que há um crescente número de doutores em DIE formados por IES brasileiras, em oposição ao período 1970-1999, no qual a maioria dos pesquisadores obteve sua formação do exterior, conforme sintetizamos no gráfico abaixo:

9 A Plataforma Lattes não disponibiliza, para o público, o ano de nascimento do pesquisador. Entendemos, também, que o ano de obtenção do doutorado pode ser mais importante para o significado de "idade" profissional do pesquisador (ou unidade analisada).

10 Essa distribuição se alinha ao que foi constatado pelo Observatório do Ensino do Direito da FGV Direito SP ao mapear o perfil do professor de Direito no Brasil. Segundo relatório publicado pelo Observatório em 2013, 62\% das funções docentes são ocupadas por docentes do gênero masculino GHIRARDI, José Garcez (Coord.) et al. Introdução: quem é o professor de Direito no Brasil? Observatório do Ensino do Direito, São Paulo, v. 1, n. 1, p. 10-11, out. 2013. Disponível em: <http://direitosp.fgv.br/sites/direitosp.fgv.br/ files/arquivos/relatorio_oed_out_2013quem_e_o_professor_de_ direito_no_brasil.pdf>. Acesso em: 13 mar. 2016.
Gráfico - Formação acadêmica, com base em ano e local de obtenção do título de doutorado

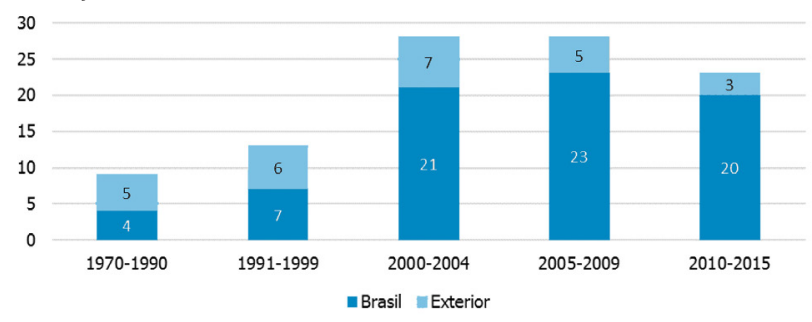

Fonte: Elaborado pelos autores, a partir de base de dados própria.

Considerando-se que parte significativa da população analisada obteve o seu título de doutorado a partir dos anos 2000, é possível identificar uma importante contribuição dos programas de pós-graduação (PPG) no Brasil para a formação dos pesquisadores e do campo em DIE no país. Por isso, entendemos relevante verificar a relação entre as IES que formam esses pesquisadores no Brasil em relação a: i) distribuição entre diferentes programas de pós-graduação (PPG) e ii) a vinculação posterior em carreira acadêmica nas mesmas IES em que obtiveram o doutorado.

Analisando-se tanto as instituições do Brasil como as do exterior, nota-se que são poucas as instituições que formam a maioria dos pesquisadores em DIE no Brasil. Colocado de outra forma, há uma concentração grande das instituições de formação destes pesquisadores. Considerando todo o universo de instituições (nacionais e estrangeiras), há predominância das universidades públicas, as quais representam $74,3 \%$ do total das IES em que os pesquisadores obtiveram os seus títulos de doutorado.

No caso das instituições estrangeiras, essa particularidade também pode estar associada ao fato de pouco mais de dois terços dos pesquisadores com formação no exterior terem concluído seu doutoramento em instituições de países europeus, os quais têm tradição de ensino superior público, conforme detalhado a seguir. Nessa relação, atenta-se, ainda, para a prevalência das instituições francesas, em especial a Université de Paris 1 (Panthéon Sorbonne). 
Gráfico - País da instituição onde pesquisadores em DIE concluíram o doutorado no exterior

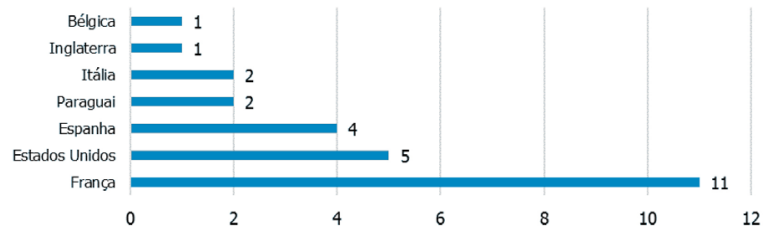

Fonte: Elaborado pelos autores, a partir de base de dados própria.

No caso das IES brasileiras em que os pesquisadores em DIE concluíram seus doutorados, verifica-se, também, um alto grau de concentração regional $(62 \%$ na região sudeste e $26,6 \%$ na região sul) e, particularmente, em uma IES específica - a Universidade de São Paulo (USP). Essa instituição responde, isoladamente, por 35,4\% das titulações de doutorado obtidas no Brasil pela população analisada.

Apesar da formação concentrada, os dados indicam que $67,9 \%$ dos pesquisadores em DIE que obtiveram seus doutorados no Brasil mudaram de organização ${ }^{11}$ na sua carreira profissional, metade destes ainda foram para organizações em outros estados ou país. Se considerarmos aqueles que obtiveram os seus títulos no exterior, tal porcentagem aumenta para 76,19\%. Tal mobilidade não pode, no entanto, obscurecer que prevalece um alto grau de endogenia ${ }^{12}$, sobretudo nas IES mais tradicionais, na área do Direito ou do Direito Internacional. Esses são os casos da Universidade de São Paulo (USP), da Pontifícia Universidade Católica de São Paulo (PUC-SP) e da Universidade Federal de Pernambuco (UFPE), com um grau mais acentuado para essas duas

11 Em alguns currículos que compõem a população, o vínculo acadêmico registrado não é com uma IES, mas com organizações de outra natureza, por isso usamos genericamente o termo "organizações". Para fins de registro, das 52 organizações três não são IES, quais sejam: Associação de Assistência aos Praianos de Guarujá, Centro de Estudos e Pesquisas em Economia e Gestão Governamental (CEPEGG) e Instituto Rio Branco (IRBr).

12 O conceito de endogenia nas universidades foi apresentado em 1960 por Bernard Berelson como referência a processos na academia dos EUA. Então, o conceito foi generalizado tal como apresentado em Braga e Venturini “[a endogenia é] uma prática de contratação onde as universidades contratam seus próprios doutores que, em virtude disto, permanecem na instituição onde estudaram, para trabalhar durante toda a sua carreira" BRAGA, M. M. S.; VENTURINI, A. E. J. F. Endogenia acadêmica em um programa de pós-graduação em direito. In: MEZZAROBA, Orides; TAVARES NETO, José Querino; VASCONCELOS, Silvia Andréia. (Org.). Direito, educação, ensino e metodologia jurídicos. Florianópolis: FUNJAB, 2013. p. 91-108. p. 94. A respeito do exemplo sobre a endogenia na Faculdade de Direito da USP e, especificamente, no seu departamento de Direito Internacional, consultar o texto supramencionado. últimas. Antes de analisarmos o grau de endogenia, apresentaremos a relação das organizações que mais empregam profissionais com atuação em DIE.

Das 1.192 faculdades de direito em atividade no Brasil $^{13}, 113$ delas apresentavam programas de pós-graduação em 2013 e, destas, apenas 31 tinham programas de doutorado ${ }^{14}$. Destas faculdades, apenas 49 IES foram indicadas como espaço de atuação profissional dos currículos que compõem a população analisada. Abaixo segue a indicação das organizações que empregam o maior número de profissionais em DIE identificados na Plataforma Lattes, sendo que isso inclui as IES e demais organizações ${ }^{15}$ :

Gráfico - Porcentagem da população atuando como profissionais

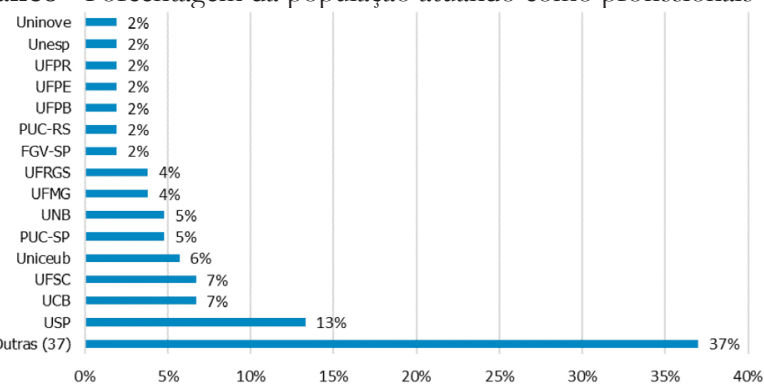

Fonte: Elaborado pelos autores, a partir de base de dados própria.

Desta população, reteremos as 15 IES que mais empregam, conforme diagnosticado no Gráfico 3. Destas 15 restam onze com programas de doutorado ${ }^{16}$ e que comporão a amostra ${ }^{17}$ sobre o grau de endogenia. A se-

13 BRASIL. Ministério da Educação. Instituições de Educação Superior e Cursos Cadastrados, Sistema e-MEC. Disponível em: <http://emec. mec.gov.br/>. Acesso em: 14 set. 2015.

14 BRASIL. Coordenação de Aperfeiçoamento de Pessoal de Nível Superior. Documento de área 2013. Disponível em: <http:// www.capes.gov.br/images/stories/download/avaliacaotrienal/ Docs_de_area/Direito_doc_area_e_comiss\%C3\%A3o_16out. pdf>. Acesso em: 14 set. 2015.

15 No total foram 52 organizações indicadas como espaço de atuação acadêmica dos 105 pesquisadores localizados na Plataforma Lattes, sendo que quatro destas não são IES (ver nota de rodapé 15). 16 As instituições sem programa de doutorado, em 2015, eram FGV-SP, UCB, Unesp e Uninove, cf. dados disponibilizados pela Capes BRASIL. Coordenação de Aperfeiçoamento de Pessoal de Nível Superior. Relação de Cursos Recomendados e Reconbecidos 2015. Disponível em: <http://conteudoweb.capes.gov.br/conteudoweb/Pro jetoRelacaoCursosServlet?acao $=$ pesquisarIes\&codigoArea $=601000$ $01 \&$ descricaoArea $=\&$ descricaoAreaConhecimento $=$ DIREITO\&d escricaoAreaAvaliacao=DIREITO>. Acesso em: 14 set. 2015.

17 Aplicamos aqui o termo "amostra" no sentido de uma parte da população analisada e que seja suficientemente representativa, para fazermos inferências sobre a totalidade da população. A respeito de critérios para a seleção de amostras no conjunto de uma população, v. JOHNSON, J. B.; REYNOLDS, H. T.; MYCOFF, J. D. Political science research methods. 6th ed. Washington: CQ Press, 2008. p. 209 e ss. 
guir, apresentamos a indicação do grau de endogenia em relação aos profissionais em DIE, com base nos dados levantados na Plataforma Lattes ${ }^{18}$, para as IES que mais empregam e que possuem programas de doutorado:

Tabela 1-Grau de endogenia em DIE nas principais IES

\begin{tabular}{|l|l|l|l|}
\hline IES & $\begin{array}{l}\text { Grau de } \\
\text { endogenia }\end{array}$ & $\begin{array}{l}\text { Total de } \\
\text { profissionais } \\
\text { em DIE }\end{array}$ & $\begin{array}{l}\text { Profissionais } \\
\text { com doutorado } \\
\text { nesta IES }\end{array}$ \\
\hline PUCSP & $\mathbf{1 0 0} \%$ & 5 & 5 \\
\hline UFPE & $\mathbf{1 0 0} \%$ & 2 & 2 \\
\hline USP & $\mathbf{7 1 , 4} \%$ & 14 & 10 \\
\hline PUC-RS & $\mathbf{5 0} \%$ & 2 & 1 \\
\hline UFPR & $\mathbf{5 0} \%$ & 2 & 1 \\
\hline UFSC & $\mathbf{2 8 , 6} \%$ & 7 & 2 \\
\hline UFMG & $\mathbf{2 5} \%$ & 4 & 1 \\
\hline UFRGS & $\mathbf{2 5} \%$ & 4 & 1 \\
\hline Uniceub & $\mathbf{1 6 , 7} \%$ & 6 & 1 \\
\hline UFPB & $\mathbf{0}$ & 2 & 0 \\
\hline UnB & $\mathbf{0}$ & 5 & 0 \\
\hline
\end{tabular}

Fonte: Elaborado pelos autores, a partir de base de dados própria.

Os dados sobre as IES que mais empregam evidenciam, também, alto grau de concentração nas universidades públicas (com 40\% dos profissionais em DIE) - assim como ocorre com as IES com mais capacidade de formação de doutores em DIE, tal qual observado acima. Esses dados sobre IES de formação, organizações que mais empregam e graus de endogenia confirmam a observação de Bernard Berelson ${ }^{19}$, de que a endogenia acadêmica tende a ser uma característica das elites universitárias e surge durante as fases iniciais do desenvolvimento dos sistemas de ensino superior e, ain$\mathrm{da}$, de que as "as taxas de endogenia nas outras universidades nunca são tão predominantes em comparação às

18 Ressaltamos que a análise sobre a endogenia aqui considera todos os currículos de profissionais de uma IES que resultaram na população de DIE identificada para fins deste artigo. Por isso, nossos números diferem em certa medida daqueles de Braga e Venturini, que por exemplo registram 100\% de endogenia no Departamento de Direito Internacional da USP BRAGA, M. M. S.; VENTURINI, A. E. J. F. Endogenia acadêmica em um programa de pós-graduação em direito. In: MEZZAROBA, Orides; TAVARES NETO, José Querino; VASCONCELOS, Silvia Andréia. (Org.). Direito, educaşão, ensino e metodologia jurídicos. Florianópolis: FUNJAB, 2013. p. 91-108. Isso ocorre porque nossos dados e forma de tratamento desses foi diferentes No levantamento para este artigo, a busca na Plataforma Lattes resultou em profissionais em DIE da USP que são professores de outros departamentos da FD/USP e, também, inclui na população aqueles obtiveram seu doutorado em outras unidades da USP - não analisadas pelas autoras Braga e Venturini.

19 BERELSON, B. Graduate education in the United States. New York: McGraw-Hill, 1960. universidades de elite, porque elas são criadas em fases posteriores do desenvolvimento do sistema de ensino superior e tendem a contratar doutores originários das referidas universidades" ${ }^{\prime 20}$.

Por fim, dos 105 currículos analisados, 96 indicaram um vínculo permanente como professor ou outro estágio mais avançado na carreira acadêmica em 2015. Nesse mapeamento, há uma distribuição majoritária na posição genérica de "professor", mas também uma distribuição equitativa entre outros níveis da carreira como professor associado, professor adjunto ou professor titular. A população analisada encontra-se, então, dividida da seguinte forma:

Gráfico - Posição na carreira acadêmica dos professores em DIE

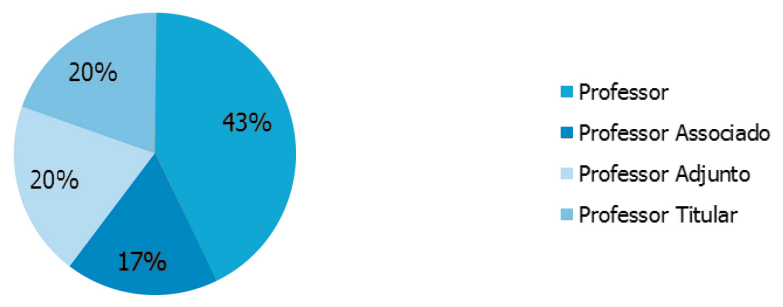

Fonte: Elaborado pelos autores, a partir de base de dados própria.

\section{DedicaÇão À PESQUiSA e AO ENSINo}

Nesta subseção, para melhor compreensão do perfil da população, o objetivo é identificar o grau de dedicação à carreira acadêmica pelo profissional em DIE. Isso compreenderá a apresentação dos dados dessa população quanto ao regime de trabalho (na academia), além dos cursos em DIE que estão registrados em seus Lattes, a dedicação à pesquisa e a vinculação destas pesquisas a núcleos registrados no $\mathrm{CNPq}$, bem como a filiação desses pesquisadores em associações acadêmicas. Os dados terão um enfoque mais quantitativo nesse primeiro momento e, nas seções seguintes, passaremos a uma análise mais qualitativa dessas informações.

20 BRAGA, M. M. S.; VENTURINI, A. E. J. F. Endogenia acadêmica em um programa de pós-graduação em direito. In: MEZZAROBA, Orides; TAVARES NETO, José Querino; VASCONCELOS, Silvia Andréia. (Org.). Direito, educação, ensino e metodologia jurídicos. Florianópolis: FUNJAB, 2013. p. 91-108. Tais números alertam para o dado apresentado por Horta (2013), sobre a relação negativa entre endogenia e produtividade acadêmica e sobre a potencial estagnação intelectual dos acadêmicos endógenos, com reduzidas conexões com o mudo externo ao da sua IES. Não iremos exploralo, no entanto, neste artigo. Esse pode ser um ponto a ser explorado em futuras pesquisas. 
O regime de trabalho da população analisada (105 currículos) não foi declarado em apenas três currículos. No restante, há uma distribuição maior entre profissionais com dedicação exclusiva (37) e profissionais horistas (30), que são as duas pontas do grau de dedicação à atividade acadêmica. ${ }^{21} \mathrm{O}$ restante se distribui quase que equitativamente entre as posições de profissionais em regime de quarenta horas (tempo integral) (19) e de vinte horas (tempo parcial) (16). Vale considerar que nas posições de profissionais horistas e em tempo parcial incluem-se aqueles profissionais sem um vínculo como professor.

A indicação de cursos ministrados pelos pesquisadores em DIE teve o objetivo, nesse primeiro momento, de identificar associações entre o regime de dedicação acadêmica do professor e a sua carga horária de ensino em temas relacionados ao DIE. Uma análise mais qualitativa sobre a identificação das áreas temáticas que estes pesquisadores em DIE ensinam e a relação dos temas dos cursos com eixos de pesquisa em DIE desta população será apresentada na Seção 5 A compreensão do campo a partir dos cursos ministrados no Brasil ("A compreensão do campo a partir dos cursos ministrados no Brasil") e na Seção 6 A compreensão do campo com base nas atividades de pesquisa no Brasil ("A compreensão do campo a partir da produção no Brasil””).

Considerando que a Plataforma Lattes tem sido uma base mais voltada para o registro sobre pesquisa ${ }^{22}$, em detrimento de ensino no nível superior, durante a pesquisa, pudemos observar que a parte relativa a cursos é aquela com menor número de informações - e, portanto, pouco precisa no tocante a datas, carga horária,

21 A grande incidência de profissionais com dedicação exclusiva dá sinais de que a área de DIE tem, nesse aspecto, um perfil distinto daquele que predomina nas faculdades de direito do Brasil. Conforme relatório do Observatório do Ensino do Direito, de 2013, apenas $6 \%$ das funções docentes nas faculdades de direito eram ocupadas por docentes em regime de dedicação exclusiva - se analisadas apenas as instituições públicas, a proporção era maior, de 30\% GHIRARDI, José Garcez (Coord.) et al. Introdução: quem é o professor de Direito no Brasil? Observatório do Ensino do Direito, São Paulo, v. 1, n. 1, p. 10-11, out. 2013. Disponível em: < http:/ / direitosp.fgv.br/sites/ direitosp.fgv.br/files/arquivos/relatorio_oed_out_2013quem_e_o_ professor_de_direito_no_brasil.pdf >. Acesso em: 13 mar. 2016. p. 78. Acreditamos que o fato de a maior parte dos pesquisadores em DIE estar em instituições públicas, ou em instituições privadas de elite, a maioria das quais possui programa de pós-graduação, influencia na formação dessa que parece ser uma peculiaridade da área. 22 As avaliações dos PPGs no Brasil consideram, com maior peso, o impacto da produção - entendida esta como publicações - em detrimento de outras atividades acadêmicas. Consequentemente, os docents tendem a valorizar aquele tipo de registro na Plataforma Lattes. número de alunos, inovação - e é também a parte menos atualizada dos currículos. A associação entre o tipo de vínculo (em termos de dedicação de horas) e horas de ensino, por exemplo, não foi possível de realizar por falta de informações neste sentido.

No tocante à dedicação à pesquisa pelos pesquisadores em DIE no Brasil, dos 105 currículos apenas 17 deles indicaram projetos de pesquisa em DIE ativos. Outro dado de relativo impacto para a área é que, dos 17 , apenas três deles estão vinculados a grupos de pesquisa registrados na base do $\mathrm{CNPq}^{23}$. Se contrastarmos esse número de grupos com o total na área do Direito no Brasil (1.203 grupos registrados), observamos que a presença ou apresentação do campo do DIE na pesquisa no Brasil (três grupos de pesquisa registrados com projeto na área) é muito reduzida no radar das plataformas de planejamento e gestão de pesquisa e desenvolvimento científico no país.

Dos 17 projetos de pesquisa atualmente ativos em direito internacional econômico no Brasil, 10 são desenvolvidos na região sudeste do Brasil. Como veremos nas seções 2 e 3 deste artigo, esta é a região com maior representatividade em DIE em números absolutos, entre 1994 e 2014. Em segundo lugar, 4 projetos de pesquisa na área são desenvolvidos no sul do país, seguida pela região centro-oeste, com 2 projetos de pesquisa. Esses indicadores geográficos são coerentes com os indicadores de produção em publicações e orientações em DIE, conforme seção 3 abaixo.

Apenas 5 projetos de pesquisa atualmente recebem algum tipo de financiamento público ou privado, contra 12 que não recebem apoio financeiro. As fontes mais frequentes de financiamento público são $\mathrm{CNPq}$ (3 pro-

23 O CNPq possui uma base pública, "Diretório dos Grupos de Pesquisa no Brasil". O CNPq especifica que "O Diretório dos Grupos de Pesquisa no Brasil constitui-se no inventário dos grupos de pesquisa científica e tecnológica em atividade no País. As informações nele contidas dizem respeito aos recursos humanos constituintes dos grupos (pesquisadores, estudantes e técnicos), às linhas de pesquisa em andamento, às especialidades do conhecimento, aos setores de aplicação envolvidos, à produção científica, tecnológica e artística e às parcerias estabelecidas entre os grupos e as instituições, sobretudo com as empresas do setor produtivo. Com isso, é capaz de descrever os limites e o perfil geral da atividade científico-tecnológica no Brasil" Conforme dados disponíveis em: < http://lattes.cnpq. br/web/dgp/o-que-e>. Acesso em: 14 set. 2015. Esta base tem como objetivo ser uma ferramenta para o planejamento e a gestão das atividades de ciência e tecnologia no Brasil. Conforme censo de 2014 elaborado pelo CNPq existiam 1.203 grupos ativos na área do Direito, envolvendo 3.079 linhas de pesquisa e 8.032 pesquisadores. http://lattes.cnpq.br/web/dgp/por-area2. Acesso em: 14 set. 2015. 
jetos), seguidos por FAPESP, CAPES e privado; cada um financiando um projeto de pesquisa. Ainda cabe destacar que o financiamento de pesquisa em DIE encontra-se canalizado para "comércio e investimento" (2 projetos), "contratos internacionais" (1 projeto), e "mercado de capitais e tributação" (2 projetos).

Por fim, as informações disponíveis sobre a filiação destes pesquisadores a associações acadêmicas, nacionais e internacionais, também são precárias na base da Plataforma Lattes. Dos 105 currículos, apenas seis pesquisadores identificam associações da área de DIE. Nesses currículos as associações mais presente são a International Law Association (ILA) e a Society of International Economic Law (SIEL), bem como o ramo regional desta última, a Red Latinoamerica de Derecho Económico Internacional.

\section{Síntese: quem SOMOS}

O quadro aproximado que pudemos obter sobre o perfil dominante do pesquisador em DIE no Brasil retrata um professional natural do Brasil, do sexo masculino, com título de doutorado obtido em IES brasileira pública, das regiões sudeste ou sul do país. Esse profissional tende a se vincular, profissionalmente, em outra IES pública como professor.

Não foi possível, no entanto, a partir deste mapeamento, obter um perfil dominante quanto ao tipo de vínculo destes profissionais com as IES em que atuam, nem sobre os estágios da carreira.

Por fim, pode-se, também, notar o baixo grau de registro de projetos de pesquisa e de grupos de pesquisa nas áreas pelos profissionais em DIE. Isso também se repete, eventualmente, como uma consequência, nos vínculos com associações acadêmicas.

\section{A COMPREENSÃo DO CAMPO A PARTIR DOS CURSOS MINISTRADOS NO BRASIL}

\section{Descrição da metodologia}

O ensino foi escolhido para mapeamento neste artigo porque entendemos que: $i$ ) considerando a crescente formação dos pesquisadores no campo em IES no
Brasil, é importante atentar para o ensino como parte deste processo de formação, e ii) as eleições temáticas deste espaço podem ter interações com a produção e a formação de pesquisadores (pontos analisados na seção 6 A compreensão do campo com base nas atividades de pesquisa no Brasil "A compreensão do campo a partir da produção no Brasil").

Não se deve, em nenhum momento, minimizar o impacto que o descaso da Plataforma Lattes com o eixo de ensino prejudica análises mais avançadas dos dados aqui apresentados. Os registros de cursos na Plataforma Lattes tanto estão limitados aos vocábulos escolhidos pelos pesquisadores, para indicarem o conteúdo de um curso, como podem ser resultado de políticas internas de cada IES ou organização ${ }^{24}$. Isso significa que a associação do título com o conteúdo do curso não é perfeita, o que também pode ser um fator a ser considerado com cautela, como resultado de um primeiro mapeamento.

A metodologia aplicada para essa dimensão do currículo Lattes valeu-se dos instrumentos de análise e classificação disponíveis no software Atlas.ti, Com base na seleção textual nos registros dos currículos sobre ensino ("citação") e da formação de "códigos"25. Selecionados, assim, os temas invocados nos títulos das disciplinas, independentemente do programa (graduação ou pós-graduação) em que são ministradas, ${ }^{26}$ e compilamos

24 Uma vez registrado o currículo do curso juntamente ao Ministério da Educação, é burocrático mudar o nome das disciplinas ministradas. Assim, o conteúdo dos cursos, ainda que sujeitos a uma ementa básica, valem-se da liberdade de cátedra do professor que ministra aquela disciplina. Considerando-se aqui nosso foco nos pesquisadores em DIE, entendemos que seja possível que muitos desses espaços de ensino mapeados possam integrar conteúdos relacionados ao campo de DIE.

25 Agradecemos aqui o registro e sistematização por Ana Laura Zuanazzi e também ao apoio técnico de Olivia Pasqualeto, bolsista TT-3 do Projeto FAPESP 2014/25776-4. A base elaborada no Atlas. ti está disponível para consulta em arquivo dos autores, mediante solicitação. Algumas leitura elucidativas sobre as funcionalidades do software e sobre o seu funcionamento são: KONOPASEK, Z. Making thinking visible with Atlas.ti: computer assisted qualitative analysis as textual practice. Forum: Qualitative Social Research, v. 9, n. 2, May 2008. Available at: <http://www.qualitative-research.net/ index.php/fqs/index>. Access on: 14 Sept. 2015; e GIBBS, Graham; FRIESE, Susanne; MANGABEIRA, Wilma C. The use of new technology in qualitative research: introduction to issue $3(2)$ of FQS. Forum: Qualitative Social Research, v. 3, n, 2, May 2002. Available at: <http://www.qualitative-research.net/index.php/fqs/ index $>$. Access on: 14 Sept. 2015. Esses textos estão disponíveis em: <http://www.qualitative-research.net/index.php/fqs/index>. Acesso em: 14 set. 2015.

26 Nesse ponto, cabe pontuar que as Diretrizes Curriculares Nacionais para os cursos de graduação em Direito. BRASIL. Ministé- 
24 "códigos" 27. Tais códigos nos trouxeram percepções distintas sobre a função das disciplinas. Por um lado, disciplinas mais tradicionais - Direito Internacional, Direito Internacional Público e Privado - por serem mais genéricas e permitirem a inclusão de muitas temáticas nos trouxeram a percepção de que são "espaços" em que os pesquisadores em DIE podem ou não integrar suas agendas na área de DIE. Por sua vez, disciplinas com títulos mais específicos - tais como, comércio, tributário, arbitragem - sugerem uma eleição temática pelo pesquisador e, ao mesmo tempo, uma aproximação maior ao campo do DIE. Por essas razões, sugerimos a seguir a apresentação dos resultados desses códigos sob diferentes leituras, como espaço e como temas de ensino.

\section{Os espaços de ensino do professor em DIE}

No conjunto de disciplinas mapeadas, aquelas mais genéricas e qualificadas aqui como "espaço" representam 60\% do universo de disciplinas mapeadas. Os títulos de cursos mais frequentes foram: "Direito Internacional Público" (registrado 167 vezes); "Direito Internacional Privado" (97 vezes); e "Direito Interna-

rio da Educação. Parecer CNE/CES n. 55, de 18 de fevereiro de 2004: Diretrizes Curriculares Nacionais para o curso de graduação em Direito. Disponível em: < http://portal.mec.gov.br/cne/arquivos/ pdf/2004/ces0055_2004.pdf>. Acesso em: 06 abr. 2016, assim como as tabelas de área do conhecimento do CNPq (CNPq. Tabela de Áreas do Conbecimento. Disponível em: <http://www.cnpq.br/ documents/10157/186158/TabeladeAreasdoConhecimento.pdf>. Acesso em: 06 abr. 2016 e da CAPES BRASIL. Coordenação de Aperfeiçoamento de Pessoal de Nível Superior. Tabela de áreas do conbecimento. Disponível em: <http://www.capes.gov.br/images/ stories/download/avaliacao/TabelaAreasConhecimento_072012. doc $>$. Acesso em: 06 abr. 2016, contemplam apenas a divisão entre Direito Internacional Público, como especialidade da subárea de Direito Público, e Direito Internacional Privado, como especialidade da subárea Direito Privado, o que tem como efeito o engessamento dos currículos das IES e das menções às disciplinas nos Currículos Lattes.

27 O software Atlas.ti permite selecionar partes de um texto e classifica-las sob um código, permitindo, ainda, a consolidação de diferentes códigos em um e a vinculação entre eles. Os códigos que consolidamos, após o registro dos títulos dos cursos, foram: análise econômica, arbitragem, comércio, concorrência, consumidor, contratos, desenvolvimento, direito comparado, direito econômico, direito internacional, direito internacional econômico, direito internacional privado, direito internacional público, direitos humanos, financiamento e negócios, globalização e governança, integração, investimento, meio ambiente, organizações internacionais, propriedade intelectual, solução de controvérsias e tributação. Além disso, foi aberto um código residual como "outros", que integrou um grupo mais disperso e diverso de temas, tais como: direito chinês contemporâneo, direito marítimo, direito notarial internacional. cional", incluindo cursos que fazem a combinação de direito internacional público e privado ${ }^{28}$ (84 vezes). Em contraponto, títulos mais direcionados para o campo, como Direito Internacional Econômico (registrado 35 vezes) - que incluiu Direito Econômico Internacional (10 vezes), Direito Internacional Econômico (23 vezes) e Direito das Relações Econômicas Internacionais (2 vezes) - e Direito Econômico (29 vezes) foram proporcionalmente menos frequentes.

Como acima indicado, consideramos que essas disciplinas mais genéricas são espaços em que os pesquisadores em DIE podem trazer suas agendas em DIE ou em tópicos ainda mais específicos relacionados ao campo do DIE. Além disso, o mapeamento evidencia que, considerando a disciplina como espaço, os cursos intitulados Direito Internacional Público são os espaços mais disponíveis para o pesquisador em DIE. A leitura reversa, também, é verdadeira, pesquisadores que entraram no nosso filtro para a população analisada (pesquisador em DIE) são também professores que com maior frequência ministram a disciplina de Direito Internacional Público, em detrimento de outras.

Tais leituras são reforçadas pelo número de pesquisadores da população analisada que já ministrou alguma vez a disciplina Direito Internacional Público: 60\% da população. Direito Internacional Econômico, por sua vez, foi ministrada, apenas, por 23 pesquisadores em DIE, o que corresponde a $22 \%$ da população analisada.

\section{Os temas de ensino do professor de DIE}

Outra apresentação dos dados é, mais do que disciplinar, temática. Isto é, os temas listados a seguir são frequentemente relacionados aos títulos das disciplinas ministradas. Há uma diversidade muito grande quando se trata destes temas. Por exemplo, codificados sob o eixo temático "integração regional”, relacionamos Mercosul, União Europeia, regionalismo, direito comunitário, blocos econômicos. Por isso, em vez de explorar esses códigos como espaços do DIE, como na seção anterior, exploramos os códigos como fruto de eleição pela população analisada, dito de outro modo, como temas de ensino, e, portanto, com potencial associação à agenda de pesquisa e especialização do pesquisador.

28 Exemplos neste sentido são disciplinas intituladas "direito internacional: público e privado", "interfaces entre direito internacional público e direito internacional privado". 
Nota-se, neste mapeamento temático, uma superposição de temas. Por exemplo, o curso "Contratos internacionais - Mercosul", pode ser tanto enquadrado sob o código "integração regional" quanto sob "contratos". Por isso, os números apresentados a seguir consideram esta superposição de temas e contagem múltipla, o que significa que não devem ser considerados absolutos ${ }^{29}$.

Gráfico - Temas de DIE em ensino

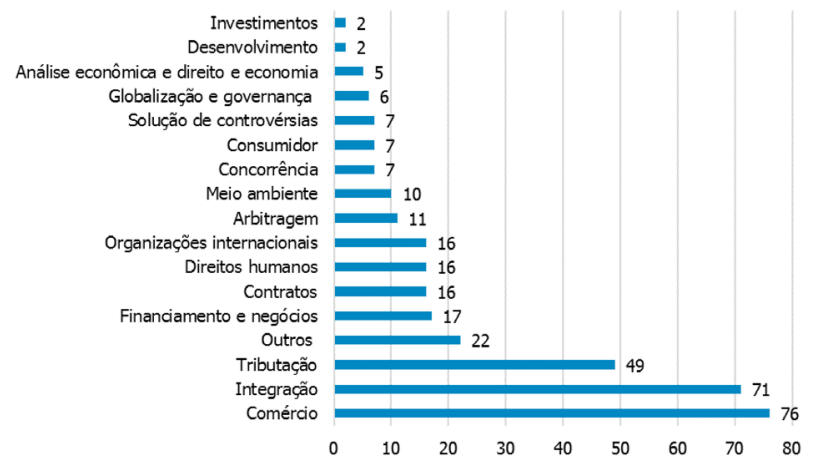

Fonte: Elaborado pelos autores, a partir de base de dados própria.

Esta apresentação nos aproxima de um dos focos deste artigo, nomeadamente: entender quais temas e objetos de pesquisa compõem o campo do DIE, pelo pesquisador da academia brasileira.

É notório que as temáticas do comércio internacional e da integração regional têm um espaço de grande destaque, em manifesta desproporção com outros temas identificados. Essas são, em geral, áreas diretamente associadas ao campo do DIE - percebe-se que, também, na academia estrangeira, esses temas recebem muita atenção. Contudo, também, chamou a atenção a frequência com que aparecem temas mais próximos ao que se entende por transações internacionais - mais conhecido como international business transactions -, que são os códigos de tributação, financiamento e negócios, contratos, concorrência, arbitragem.

Por fim, também não era trivial antever que os temas "meio ambiente", "consumidor" e "direitos humanos" iriam assumir códigos próprios e com uma participação

29 O código "comércio" integra todas as disciplinas que registram os vocábulos comércio (internacional, exterior), comercial e aduaneiro. Ao código "integração" associamos Mercosul, União Europeia, regionalismo, direito comunitário e blocos econômicos. Ao código "tributação", associamos tributário/a e tributação. O código "financiamento e negócios" integra um conjunto mais amplo de vocábulos: negócios, financeiro, empresarial, empresas, mercado, finanças. Ao código "meio ambiente", foram associados: ambiental, mudanças climáticas, desenvolvimento sustentável. A "solução de controvérsias", os vocábulos jurisdicionalização, solução de controvérsias, conflitos. relativa no mapeamento da agenda de ensino do pesquisador em DIE.

\section{A cronologia do ensino em DIE no Brasil e seus agentes}

Um outro foco deste artigo é entender a relação entre "quem somos" e "o que fazemos". Para realizar essa análise, nós selecionamos algumas correlações. Primeiramente, consideramos importante entender a relação da temática na área de ensino no tempo. Para tanto, consideramos o período analisado em blocos de cinco/ seis anos: 1994-1999, 2000-2004, 2005-2009 e 20102014. Com base nessa periodização, consideramos as disciplinas ministradas pelos pesquisadores em DIE. Um primeiro objetivo foi verificar o número de disciplinas relacionadas ao campo do DIE e suas alterações entre tais períodos.

A análise dos currículos da população de DIE mostra que é crescente o número de cursos e de pesquisadores envolvidos em ao menos um curso relacionado a DIE. No período 1994-1999, havia 37 professores da população ministrando disciplinas potencialmente relacionadas a DIE. Esse número mais do que dobrou em dez anos: no período 2010-2014, havia 87 professores envolvidos. Considerando-se a população total analisada de 105 pesquisadores, isso significa que, em 2014, 83\% da população que vincula os currículos na Plataforma Lattes ao campo de DIE, também, atuava no nível de ensino com temas correlatos ao campo. Isso, também, significa que 16 pesquisadores da população, em nenhum momento, em relação aos períodos analisados, ministrou disciplinas relacionadas ao campo do DIE.

Outro ponto analisado foi o tempo de obtenção do doutorado em relação ao período analisado. Se no primeiro período (1994-1999), 62\% dos professores que ministravam disciplinas ainda não tinham o título de doutorado, essa situação se inverte nos últimos períodos. No último período completo, 2005-2009, 88\% dos professores já tinham obtido o título ou estavam em vias de obtê-lo ${ }^{30}$. Esses dados sugerem que a crescente formação de pesquisadores em DIE doutores (conforme Gráfico - Formação acadêmica, com base em ano e local de obtenção do título de doutorado) impacta no

30 Essa análise foi prejudicada para o último período 2010-2014 pelo recorte inicial da nossa população, integrada apenas por doutores até 2014. 
professor que o aluno tem em sala de aula, cada vez mais titulado.

Por outro lado, não obstante a crescente titulação de pesquisadores em DIE, observa-se que a atividade de ensino em DIE se mantém concentrada em IES públicas (variou de 70\%, em 1990-1994, para 61,5\% 2005-2009, retornando a 70\% no último período, de 2010-2014) e nas IES das regiões Sudeste e Sul do Brasil (média de 75\% entre os períodos).

Não foi possível observar, no entanto, um perfil dominante deste professor. De uma forma geral, houve uma distribuição quase que equitativa entre os professores com dedicação exclusiva ou integral e aqueles com dedicação parcial ou horistas, assim como entre professores em diferentes momentos da carreira.

\section{Síntese: o que o mapeamento do ensino mostra?}

Os registros nos currículos não parecem fugir às regras dos registros na área de ensino na Plataforma Lattes. Ou seja, as informações são precárias, pela desatualização, imprecisão e limitações formais dos registros junto a autoridades públicas. Considerando-se isso, fizemos alguns registros mais simples e poucas associações dos dados.

A primeira apreciação foi de que os espaços de ensino mais tradicionais - como as disciplinas intituladas Direito Internacional, Direito Internacional Público e Direito Internacional Privado - são predominantes no currículo dos pesquisadores em DIE. Assim, é possível que temas de Direito Internacional Econômico sejam trabalhados nessas disciplinas, porém invisíveis ao nosso mapeamento. $\mathrm{O}$ mapeamento temporal agregou o dado de que o número de disciplinas específicas em DIE cresceu na sequência dos períodos analisados.

A segunda apreciação foi de que, no conjunto da especificidade de temas, aqueles relacionados ao comércio e à integração foram dominantes. Por outro lado, ficaram evidentes algumas ausências não esperadas pelos pesquisadores no início da pesquisa. No mapeamento de frequência, foi muito baixo o registro de disciplinas referentes a investimento, propriedade intelectual (PI) e questões monetárias (esta, por estar associada a financeiro, foi registrada em uma das disciplinas codificadas com "financiamento e negócios"). E, também, a ausência do tópico corrupção na agenda de ensino dos pes- quisadores de DIE. Novamente, isso não significa que os temas não sejam abordados de alguma forma pelos professores em seus planos de ensino - significa apenas que os pesquisadores não comunicam isso em seus registros de ensino na Plataforma Lattes.

Por fim, a terceira apreciação se refere ao perfil do professor. O que se observa é que aquele professor que declara mais disciplinas em DIE no Brasil está vinculado a IES públicas, baseadas no sudeste e no sul do Brasil e, crescentemente, tem uma titulação maior (doutorado) no momento de aplicação do curso.

No início da pesquisa, aventamos a possibilidade de integrar nessa seção de ensino a preparação de equipes para competições internacionais. Identificamos, no entanto, o envolvimento de apenas dois professores em competições, em algum momento de suas carreiras. Consideramos que diferentes situações podem justificar este resultado: i) a falta de espaço e prestígio pela Plataforma Lattes e agências de avaliação podem servir de desestímulo, seja para o registro da atividade, seja para o envolvimento nesse tipo de espaço de formação; e ii) esse papel pode estar sendo cumprido, predominantemente, por alunos ou ex-alunos de pós-graduação que não constam da nossa população.

\section{A COMPREENSÃo dO CAMPO COM BASE NAS ATIVIDADES DE PESQUISA NO BRASIL}

\section{Descrição da metodologia}

Nessa seção, procuramos traçar um perfil da pesquisa em DIE no Brasil. Três são os eixos de avaliação da produção acadêmica que adotamos, os quais avaliamos de modo quantitativo e, no aspecto temático, qualitativo: ) a publicação de livros, coletâneas e capítulos de livros; ii) a publicação de artigos em periódicos científicos; e iii) a relação de dissertações e teses orientadas pelo pesquisador. Nos três eixos, analisaremos a distribuição temática, temporal e geográfica dos dados encontrados no período 1994-2014.

Assim como para a produção em ensino, a metodologia para o mapeamento da produção em pesquisa partiu dos registros feitos pesquisadores em DIE em seus currículos na Plataforma Lattes. Diferentemente de como foi feito para produção em ensino, nessa etapa 
não utilizamos o Atlas.ti. Devido à necessidade de se classificar cada publicação e trabalho orientado, o currículo de cada pesquisador foi, individualmente, consultado, em uma etapa de listagem da producão. Concluída a listagem, passou-se à etapa de classificaşão da produção, que também foi feita manualmente. Procedeu-se do seguinte modo: cada item recebeu uma primeira classificação, mais específica, diretamente relacionada com o seu título; após, agruparam-se os itens afins, a eles atribuindo uma segunda classificação, generalizadora - como, por exemplo, Integração, Comércio, Contratos internacionais ${ }^{31}$. Concluída esse etapa, teve início a análise da produção, que foi feita por meio da função Tabela Dinâmica do Microsoft Excel 2013. Os resultados são apresentados a seguir.

\section{Livros, coletâneas e capítulos sobre DIE}

É conhecida a preferência na área do Direito para publicação de sua produção em livros, coletâneas e capítulos de livros, diferentemente de outras áreas das Ciências Sociais. De uma forma geral, tal preferência está associada à tradição do campo e ao perfil doutrinário da produção pelo jurista no Brasil ${ }^{32}$. Isso, no entanto, não se confirmou no caso dos pesquisadores em DIE, para os quais obtivemos o registro total de 270 livros, coletâneas e capítulos de livros e 515 artigos publicados em periódicos.

No que tange aos livros e capítulos de livros, foram 39 livros publicados, 60 coletâneas organizadas e 171 capítulos de livros registrados pelos pesquisadores em DIE, no período 1994-2014. Toda essa produção de alguma forma se relaciona com temáticas do campo do DIE. Do total dessas publicações, 233 foram em português e 231 por editoras nacionais, o que confirma a tese de Kunz sobre a preferência da produção em

31 Na categoria 'Outros', alocamos a produção que não se encaixava nos eixos temáticos criados para reunir a produção nos temas que encontramos em mais abundância na base de dados. Nessa categoria residual há, por exemplo, textos, sempre em quantidade não expressiva, isto é, em número inferior a cinco, que versam sobre proteção dos direitos do consumidor no comércio internacional eletrônico, pagamentos internacionais, análise institucional da OCDE, política econômica dos BRICS, análises de teoria do DIE, DIE e desenvolvimento, DIE e meio ambiente, governança econômica e mercado de capitais.

32 KUNZ, I. Dinâmica de produção de conbecimento na área de direito no Brasil. 2011. 245 f. Tese (Doutorado) - Programa de Pós-Graduação em Política Científica e Tecnológica, Instituto de Geociências, Universidade Estadual de Campinas, Campinas, 2011. p. 135-155. direito, em meios nacionais e em língua portuguesa ${ }^{33}$. Os demais idiomas em que se encontra publicada essa produção são, na ordem de importância, inglês (24 produções), espanhol (11 produções) e francês e italiano (1 produção cada).

Assim como foi identificado em outros espaços, a produção em livros, coletâneas e capítulos de livro aumentou, significativamente, nos períodos selecionados: em 1994-1999, foram registradas 31 publicações; em 2000-2004, 57 publicações; em 2005-2009, 76 publicações; e, em 2010-2014, 106 publicações.

Os resultados nesse grupo de publicações remete a um universo de pouco mais da metade da população analisada: 59 pesquisadores em DIE (56,2\%) responderam por todas as publicações em livros, coletâneas e capítulos de livros. Dentre esses, apenas 6 pesquisadores publicaram mais de 10 resultados nesta categoria, durante o período analisado. Todos os 59 pesquisadores encontram-se nas regiões Sudeste e Sul do país e 83,3\% estão em IES públicas - dados que reforçam a percepção de concentração intelectual na área de DIE em algumas regiões e institutições do país.

Foi também elaborada uma classificação da produção dos 270 resultados em livros, coletâneas e capítulos de livros, por eixos temáticos, conforme a metodologia indicada acima.

Gráfico - Temas de DIE nos livros, coletâneas e capítulos

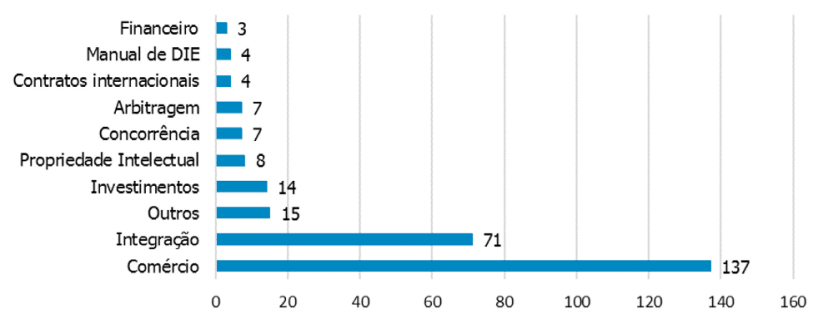

Fonte: Elaborado pelos autores, a partir de base de dados própria.

A distribuição desses temas é muito similar entre os diferentes meios de divulgação (livros, coletâneas e capítulos de livros). Em torno de 50\% da produção em cada um dos canais se destina ao eixo temático de comércio, na sequência o tema de integração ocupa entre $20 \%$ e $30 \%$ da produção, seguidos de uma margem entre $3 \%$ e $5 \%$ em cada um dos espaços para, individualmente, os temas de investimento, propriedade intelectual, arbitra-

33 KUNZ, I. Dinâmica de produção de conbecimento na área de direito no Brasil. 2011. 245 f. Tese (Doutorado) - Programa de Pós-Graduação em Política Científica e Tecnológica, Instituto de Geociências, Universidade Estadual de Campinas, Campinas, 2011. p. 158. 
gem e concorrência. Nos casos de livros e coletâneas, há uma particularidade que atende a cada um dos meios de publicação. No caso de livros, 4 deles foram classificados sobre temas gerais em DIE e entendemos que assumem mais um perfil de manual da área. No caso das coletâneas, em torno de 6 delas também apresentam coberturas gerais de temas específicos, mas com chamadas para sua atualidade, com base no uso de verbetes como "novos" e "desafios".

Em um recorte mais vertical sobre os temas elencados no Gráfico 6 , conseguimos observar os conjuntos que foram agregados em cada eixo. No eixo temático de comércio, em que há uma grande concentração da produção (136), 48,5\% das publicações (66 delas) estão voltadas para análises da regulamentação pela Organização Mundial do Comércio (OMC); 13,2\% das publicações (18) concentram-se na interface do comércio internacional com temas sociais - tais como desenvolvimento, meio ambiente, questões trabalhistas e direitos humanos; 15 produções focam no debate multilateralismo/ regionalismo ou acordos preferenciais de comércio; 7 produções em temas de defesa comercial (antidumping, subsídios e medidas compensatórias e salvaguardas); 4 produções apenas analisam sistemas de solução de controvérsias em geral; e o restante da produção se dispersa entre questões bilaterais.

No eixo de integração, a produção relacionada a Mercosul é determinante, respondendo por 51 produções do total de 70 . No eixo residual de "outros", há uma grande diversidade de temas como internacionalização de empresas, direito marítimo, até títulos genéricos sobre DIE e seus desafios. No caso das temáticas de investimentos e propriedade intelectual, as suas sub-temáticas também são muito diversas - o que chama a atenção nesses casos é que em investimentos não há a prevalência do debate sobre tratados bilaterais e o sistema de controvérsias investidor-estado, tal como na produção estrangeira, nem em PI há um número significativo de análises relacionadas ao sistema multilateral da OMC. Em arbitragem, por outro lado, há uma grande concentração, novamente, no espaço do Mercosul (3 produções do total de 7) e na questão da arbitragem comercial internacional. Em concorrência, a maior parte da produção apresenta títulos bastante genéricos que não permitiram uma verticalização da análise. Em contratos, por fim, o tema prevalecente é o das regras da Convenção de Viena sobre a Compra e Venda de Mercadorias (conhecida pela sigla em inglês, CISG).
Apesar de o gráfico temático (Gráfico - Temas de DIE nos livros, coletâneas e capítulos) indicar quais temas, historicamente, têm mais espaço na produção em DIE no Brasil, observamos que esses números absolutos não se prestavam à investigação de eventuais tendências de produção em DIE em livros, coletâneas e capítulos de livro. Dito de outro modo, não se prestavam para investigar se há temas que, nessa modalidade de produção, adquiram progressivo espaço no campo, ganhando a preferência dos pesquisadores em determinados momentos da história. Na Tabela 2, apresentamos a periodização da produção, por eixos temáticos.

Tabela 2 - Preferências temáticas, por período, nas publicações em livros, coletâneas e capítulos de livros

\begin{tabular}{|c|c|c|c|c|c|}
\hline Temas & $\begin{array}{c}1994- \\
1999\end{array}$ & $\begin{array}{l}2000- \\
2004\end{array}$ & $\begin{array}{c}2005- \\
2009\end{array}$ & $\begin{array}{l}2010- \\
2014\end{array}$ & Total \\
\hline Arbitragem & 1 & 2 & 2 & 2 & 7 \\
\hline Comércio & 14 & 22 & 38 & 63 & 137 \\
\hline Concorrência & 1 & 3 & 2 & 1 & 7 \\
\hline $\begin{array}{l}\text { Contratos } \\
\text { internacionais }\end{array}$ & - & - & 1 & 3 & 4 \\
\hline Financeiro & - & 2 & 1 & - & 3 \\
\hline Integração & 14 & 24 & 15 & 18 & 71 \\
\hline Investimentos & - & - & 5 & 9 & 14 \\
\hline Manual de DIE & 1 & 1 & 1 & 1 & 4 \\
\hline Outros & - & 3 & 5 & 7 & 15 \\
\hline $\begin{array}{l}\text { Propriedade } \\
\text { Intelectual }\end{array}$ & - & - & 6 & 2 & 8 \\
\hline Total & 31 & 57 & 76 & 106 & 270 \\
\hline
\end{tabular}

Fonte: Elaborado pelos autores, a partir de base de dados própria.

Nota-se que comércio foi o tema predominante em todos os períodos. Em relação a esse eixo temático, houve um número maior de produção em livros, coletâneas e capítulos de livros no período 2010-2014, o que acompanha o aumento da produção como um todo.

Destacamos, na tabela, o período em que a produção em cada eixo temático foi mais intensa, considerado o total de produção específico naquele tema. Além disso, nota-se que o último período foi o de maior produção nos eixos de comércio, contratos, investimentos e "outros". Dado que o código "outros" tem caráter residual, sugere-se que temas mais novos ao campo possam ser trabalhados aqui, como é o caso dos temas corrupção e internacionalização de empresas.

Mais adiante, usaremos, também, essas informações para contrastar os eixos temáticos em outros espaços 
de produção dos pesquisadores em DIE, bem como em relação aos grupos de pesquisa e financiamento de projetos.

\section{Artigos sobre DIE publicados em periódicos científicos}

Entre 1994 e 2014, o a população analisada publicou 515 artigos em periódicos científicos. Desse total, $82 \%$ foram em periódicos nacionais e $77 \%$ em português, o que mais uma vez confirma a tese de Kunz ${ }^{34}$. Além da publicação no idioma português, a população em DIE no Brasil tem publicado, em ordem de preferência, em inglês (13\%), em espanhol (7\%) e em francês (3\%). Esta produção se associa a cenários apresentados anteriormente de crescente formação e produção acadêmica em DIE no Brasil: se no período 1994-1999 foram publicados 70 artigos em periódicos científicos; em 2000-2004, foram 121; em 2005-2009, 155; e, em 2010-2014, 169.

Do total da população (105 pesquisadores), apenas 71 deles publicaram, em periódicos científicos, artigos com temas relacionados a DIE. Se considerarmos os pesquisadores mais produtivos desse grupo - acima de 20 artigos sobre temas gerais no período analisado (1994-2014) - restam 30 pesquisadores da população analisada. Nota-se que essa produção, assim como na formação e área de ensino, também se concentra nas regiões Sudeste e Sul do país $(73,3 \%)$ e em IES públicas $(63,3 \%)$. Daqueles 30, apenas 8 deles dedicam mais de $50 \%$ de sua produção de artigos em periódicos, para temas relacionados ao campo do DIE. Isso sugere que há uma concentração grande da produção neste tipo de veículo, no campo de DIE, em alguns pesquisadores da academia brasileira.

Outra análise aplicada aos dados levantados sobre a publicação em periódicos científicos foi relativa aos temas mais presentes nesta produção. Abaixo sistematizamos os temas que predominaram:

34 KUNZ, I. Dinâmica de produção de conbecimento na área de direito no Brasil. 2011. 245 f. Tese (Doutorado) - Programa de Pós-Graduação em Política Científica e Tecnológica, Instituto de Geociências, Universidade Estadual de Campinas, Campinas, 2011. p. 158.
Gráfico - Temas de DIE nos artigos em periódicos científicos

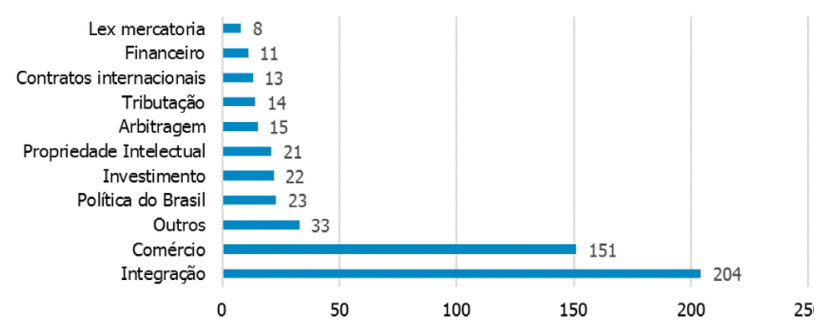

Fonte: Elaborado pelos autores, a partir de base de dados própria.

Os temas de integração e comércio, novamente, assumem destaque na produção da população analisada, invertendo a projeção de integração sobre comércio no caso dos periódicos em relação aos livros, coletâneas e capítulos de livros. Sobre integração, especificamente, neste amplo universo, mais da metade é referente a "Mercosul" (123 artigos), na sequência outros processos de integração como Área de Livre Comércio das Américas (ALCA) e North America Free Trade Agreement (NAFTA) são analisados (28 artigos), a comparação entre União Europeia e Mercosul (27 artigos), apenas o processo de integração da União Europeia e, por fim, 15 artigos se concentram em análises gerais sobre processos de integração.

No eixo de comércio, 93 dos 151 artigos indicam o foco na regulamentação pela Organização Mundial do Comércio. Na sequência, a produção se foca na fronteira entre a regulamentação do comércio e outros temas sociais como meio ambiente, questões trabalhistas, direitos humanos e desenvolvimento (23 artigos). Os temas sobre acordos preferenciais de comércio ( 9 artigos) e regionalismo e multilateralismo (8 artigos) pautam um terceiro eixo subtemático. Por fim, os demais 18 artigos tratam de temas diversos, como questões aduaneiras, tributação, relações bilaterais específicas, direito marítimo, entre outros. ${ }^{35}$

A categoria residual de "Outros" com 33 artigos compreende uma ampla gama de temas que não formam grupos temáticos, para serem isolados. Dentre os temas incluídos estão: análises gerais sobre DIE, corrupção, cooperação, BRICs, Consenso de Washington, entre outros.

35 O número especial da Revista de Direito Internacional dedicado ao tema Direito Internacional Econômico (edição v. 10, n. 1, 2013) reúne um conjunto de artigos que, em nosso entendimento, é ilustrativo da preferência dos pesquisadores de DIE por certos temas, como identificado no mapeamento. $\mathrm{Na}$ referida edição, predominam os artigos sobre comércio internacional (7 artigos), seguido por artigos sobre investimento estrangeiro ( 3 artigos), concorrência (2 artigos), Mercosul (1 artigo), contratos internacionais (1 artigo) e arbitragem comercial (1 artigo). 
Na segunda faixa de temas com produção em torno de 20 artigos, chama a atenção a presença de temas que não apareceram na parte de ensino, tais como política do Brasil, investimentos e propriedade intelectual. Por sua vez, outros temas que tiveram mais destaque na seção de ensino, tais como arbitragem, tributação e contratos, contaram com poucos registros na produção em periódicos científicos.

A fim de prevenir a ilusão de tendências de produção com base nos números absolutos do gráfico temático (Gráfico - Temas de DIE nos artigos em periódicos científicos), apresentamos a distribuição da produção temática em periódicos, em determinados momentos da história.

Tabela 3 - Temáticas, por período, nas publicações em periódicos científicos

\begin{tabular}{|c|c|c|c|c|c|}
\hline Temas & $\begin{array}{c}1994- \\
1999\end{array}$ & $\begin{array}{l}2000- \\
2004\end{array}$ & $\begin{array}{c}2005- \\
2009\end{array}$ & $\begin{array}{c}2010- \\
2014\end{array}$ & Total \\
\hline Arbitragem & 1 & 4 & 5 & 5 & 15 \\
\hline Comércio & 17 & 24 & 56 & 54 & 151 \\
\hline $\begin{array}{l}\text { Contratos } \\
\text { internacionais }\end{array}$ & 4 & 1 & 3 & 5 & 13 \\
\hline Financeiro & 3 & 5 & 1 & 2 & 11 \\
\hline Integração & 35 & 64 & 61 & 44 & 204 \\
\hline Investimento & 4 & 3 & 4 & 11 & 22 \\
\hline Lex mercatoria & 1 & 2 & - & 5 & 8 \\
\hline Outros & - & 6 & 7 & 20 & 33 \\
\hline Política do Brasil & 3 & 4 & 7 & 9 & 23 \\
\hline $\begin{array}{l}\text { Propriedade } \\
\text { Intelectual }\end{array}$ & 2 & 4 & 5 & 10 & 21 \\
\hline Tributação & - & 4 & 6 & 4 & 14 \\
\hline Total & 70 & 121 & 155 & 169 & 515 \\
\hline
\end{tabular}

Fonte: Elaborado pelos autores, a partir de base de dados própria. A base está disponível para consulta, mediante solicitação.

Os dados da Tabela 3 favorecem o contraste de alguns períodos e temas. Se a temática de comércio tem ganhado projeção crescente nos quatro períodos apresentados, a temática de integração tem perdido. Os eixos temáticos de integração e financiamento tiveram momentos de maior publicação em periódicos no período 2000-2004, perdendo a vitalidade da produção nos últimos anos. Os eixos de contratos internacionais e lex mercatoria que, no período 1994-1999, tinham algum espaço, perderam o fôlego nos dez anos seguintes, mas retornaram à agenda de publicações em periódicos no último período, com mais vigor. Também a produção do último período (2010-2014) evidencia o crescimento de publicações em eixos antes pouco explorados, tais como investimento, propriedade intelectual, política do Brasil e arbitragem.

\section{A formação de recursos humanos em DIE, em nível de pós-graduação}

A análise de dissertações e teses sobre direito internacional econômico orientadas por professores/ pesquisadores integrantes da população analisada neste artigo traz resultados que, em alguns aspectos, repetem padrões identificados nas seções anteriores.

O total de dissertações e teses orientadas no período analisado é de 270 , sendo que esta produção foi crescente até 2009. O total se divide em 225 dissertações de mestrado e 45 teses de doutorado. No período 2005-2009, as dissertações e teses relacionadas a DIE e orientadas por professores em DIE atingiram o pico de 99 produções; no período de 2010-2014, esse número retrocedeu para 70. O gráfico abaixo elucida esta evolução, em base anual:

Gráfico - Número de teses e dissertações em DIE, por ano (19942014)

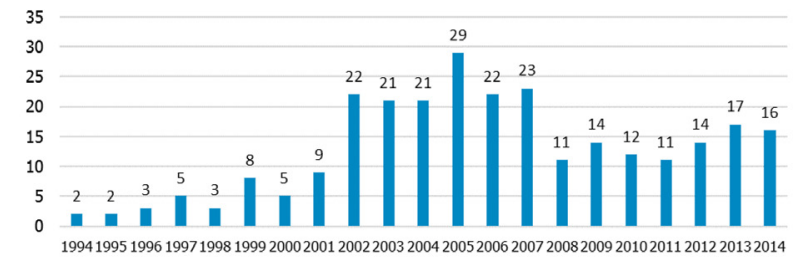

Fonte: Elaborado pelos autores, a partir de base de dados própria.

Também, as orientações estão concentradas nas regiões no Sudeste e Sul do país, que, em conjunto, responderam por $81 \%$ das dissertações e teses defendidas entre 1994-2014. Mas, diferentemente de outras produções acima analisadas, não observamos a mesma predominância das IES públicas, conforme indicado no gráfico a seguir.

Gráfico - IES em que teses e dissertações em DIE foram defendidas (1994-2014)

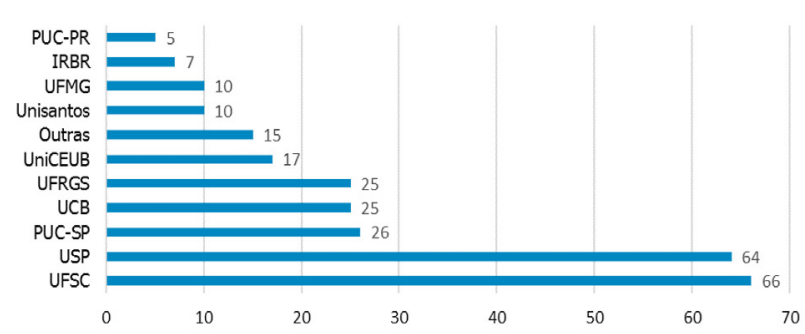

Fonte: Elaborado pelos autores, a partir de base de dados própria. 
É interessante notar que o gráfico acima também nos permite identificar a melhor produtividade na relação professor/orientandos, ou seja, na formação de capital humano por meio de orientações em pós-graduação. Ao contrastar o número de orientações com o número de profissionais por IES, aquelas que mais se destacam em ordem de maior produtividade para menor, no campo do DIE, são: i) Unisantos; ii) UFSC; iii) UFRGS; iv) PUC-SP; v) PUC-PR; vi) USP; vii) UCB; viii) Uniceub; e ix) UFMG. O fato de a USP e a UFSC formarem mais de um terço dos pós-graduandos em DIE está relacionado com o tamanho de seus corpos docentes (o primeiro e o terceiro maiores do mapeamento obtido (Gráfico 3 acima). Entretanto, o índice de produtividade também indica que corpos docentes pequenos podem formar um número relevante de recursos humanos, como foi o caso da Unisantos.

Tal relação de produtividade não deve, no entanto, ocultar um alto número de orientações por professor em algumas IES com produtividade média. O que pudemos observar é que apenas 9 professores em DIE orientaram mais de 10 dissertações e teses no período de 1994-2014. Isso reproduz a mesma concentração de produtividade que observamos no caso das publicações. Contudo, dentre os professores em DIE, apenas dois dos mais produtivos em publicações também estão entre os mais produtivos em orientações, o restante do grupo não coincide - apesar de alguns compartilharem o mesmo espaço de trabalho.

Outro nível de análise que priorizamos sobre as teses e dissertações foi o seu campo temático. Essa aproximação seguiu a metodologia indicada no início dessa seção 3 e resultou nos seguintes números e proporções:

Gráfico - Temas de DIE em teses e dissertações (1994-2014)

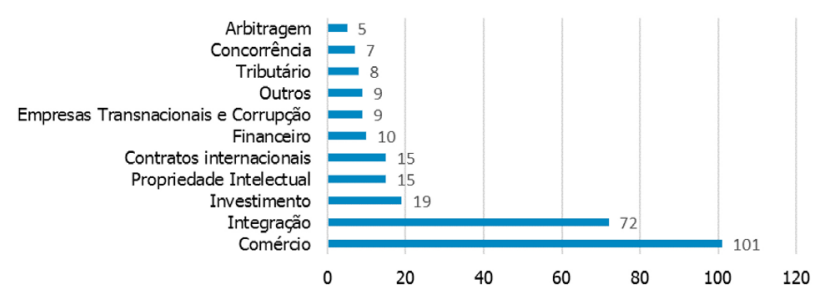

Fonte: Elaborado pelos autores, a partir de base de dados própria.
O primeiro resultado observado é a predominância de teses e dissertações sobre a temática comércio (101). No mesmo sentido da produção de seus orientadores, parte significativa dessa produção se concentrou sobre a regulamentação da Organização Mundial do Comércio (76), sendo que a quebra para outros subtemas é gritante. O segundo subtema mais pesquisado nessas teses e dissertações é o da interface entre comércio e temas sociais - meio ambiente, direitos humanos, cláusula trabalhista - que totalizam 7 produções apenas. Outros dois subtemas que acompanham esta tendência são aqueles relacionados ao comércio exterior (6) e o debate sobre multilateralismo e regionalismo (5).

No eixo de integração, que também tem um papel de destaque neste perfil de produção, assim como nas dos orientadores/as, predomina da mesma forma a subtemática do Mercosul (54), seguida em desproporção de União Europeia (5).

Em alguns outros eixos, a diversidade interna subtemática mapeada foi muito grande, de forma que optamos por não decompor tais eixos. Esses são os casos dos eixos investimento, contratos, tributário, concorrência e arbitragem.

Nos casos de propriedade intelectual e de financeiro, apesar de os números absolutos serem baixos, vale destacar o domínio dos subtemas "patentes" (7) e "transferência de tecnologia" (4), em propriedade intelectual, e "Fundo Monetário Internacional" (5), em financeiro. Esses subtemas também se alinham com a produção docente mapeada acima.

Um eixo que não havia aparecido com destaque nas produções dos orientadores e nas teses e dissertações ganhou espaço nos últimos anos é o de empresas transnacionais e corrupção. Neste eixo, há três subtemas que compartilham o espaço: lavagem de dinheiro, corrupção e empresas transnacionais.

Considerando as limitações, indicadas acima, do gráfico temático (Gráfico - Temas de DIE em teses e dissertações (1994-2014) abaixo apresentamos a periodização de 5-6 anos proposta e os momentos em que predominaram as produções em determinados eixos temáticos também para o caso das produções em dissertações e teses: 
Tabela 4 - Preferências temáticas das teses e dissertações em DIE, por período

\begin{tabular}{|c|c|c|c|c|c|}
\hline Temas & $\begin{array}{c}1994- \\
1999\end{array}$ & $\begin{array}{l}2000- \\
2004\end{array}$ & $\begin{array}{c}2005- \\
2009\end{array}$ & $\begin{array}{c}2010- \\
2014\end{array}$ & Total \\
\hline Arbitragem & - & 1 & 2 & 2 & 5 \\
\hline Comércio & 3 & 25 & 42 & 31 & 101 \\
\hline Concorrência & - & - & 2 & 5 & 7 \\
\hline $\begin{array}{l}\text { Contratos } \\
\text { internacionais }\end{array}$ & 3 & 5 & 5 & 2 & 15 \\
\hline $\begin{array}{l}\text { Empresas } \\
\text { Transnacionais e } \\
\text { Corrupção }\end{array}$ & - & 1 & 4 & 4 & 9 \\
\hline Financeiro & 1 & 1 & 6 & 2 & 10 \\
\hline Integração & 12 & 31 & 19 & 10 & 72 \\
\hline Investimento & 2 & 5 & 9 & 3 & 19 \\
\hline Outros & - & 4 & 3 & 2 & 9 \\
\hline $\begin{array}{l}\text { Propriedade } \\
\text { Intelectual }\end{array}$ & 2 & 2 & 6 & 5 & 15 \\
\hline Tributação & - & 3 & 1 & 4 & 8 \\
\hline Total & 23 & 78 & 99 & 70 & 270 \\
\hline
\end{tabular}

Fonte: Elaborado pelos autores, a partir de base de dados própria.

O que observamos neste detalhamento é que a representação do tema de comércio é preponderante e foi muito alta nos dois últimos períodos, com uma leve redução no período 2010-2014 - tal qual a publicação de artigos em periódicos científicos pelos orientadores. Outros eixos em sintonia com a produção docente são os de propriedade intelectual e tributação, com pequeno incremento nos últimos anos.

Os eixos de investimento, financeiro e concorrência parecem dialogar, de forma diferente, com a produção docente. Em investimento, o aumento da produção de dissertação e teses, em 2005-2009) antecedeu o aumento da produção docente, que foi mais forte no período 2010-2014. No eixo financeiro, por outro lado, a produção discente (2005-2009) foi mais forte no período subsequente ao seu destaque na produção docente (20002004). E, em concorrência, apesar de tanto a produção docente quanto discente ter aumentado nos últimos anos, isso se deu com mais ênfase - ou mais produções - no campo discente.

Por fim, um grupo de três outros temas parecem assumir caminhos inversos aos dos orientadores. Observa-se uma maior produção de dissertações e teses no eixo de contratos internacionais do que na produção dos professores; e o inverso se dá no eixo de arbitragem, em que identificamos mais interesse de produção pelos professores. Outro tema de destaque é o eixo de empresas transnacionais e corrupção que ganha um espaço de destaque já na produção das teses e dissertações (9), em contraponto com a produção dos professores (5, no total de livros, coletâneas e artigos).

\section{Síntese: o que o mapeamento da pesquisa mostra?}

Para avaliar a produção do eixo de pesquisa, optamos por distinguir três tipos de atividades: duas diretamente ligadas à produção do pesquisador em DIE, em livros, coletâneas, capítulos de livros e artigos em periódicos; e outra relacionada à formação e que indiretamente afeta a produção em DIE, com base nas orientações de dissertações de mestrado e teses de doutorado.

Em termos quantitativos, esses mapeamentos chamam a atenção sob dois aspectos, que têm um traço comum e dissonante. Expliquemos: observamos um alto índice de publicações, considerando inclusive o contraponto com a tradição da área do direito de publicação preferencial em periódicos científicos; a formação de capital humano, com base em orientações, no entanto, é baixa. Se considerarmos a população de 105 pesquisadores, 785 publicações no total do período (1994-2014), obtemos um índice de 0,35 publicação/ano/pesquisador. No caso das 270 orientações, esse mesmo cálculo traz uma média de 0,12 orientações/ano/pesquisador. Um ponto comum e dissonante desses dois índices é que a população de pesquisadores mais produtivos é concentrada, porém ela não coincide totalmente.

Observamos, também que na relação entre os dois eixos - publicação e orientação - há um diálogo que se alimenta ou retroalimenta, ou seja, os temas de pesquisa dos orientadores influenciam a agenda dos orientandos, mas o inverso, também, é verdadeiro para algumas linhas (como foi o caso de investimento).

Em específico sobre os resultados de publicação, o que o mapeamento indicou é que os pesquisadores na área têm dado preferência à publicação em periódicos, em contraponto a livros. E, no caso dos livros, mais a coletâneas do que livros monográficos. A identificação de publicações mais próximas do formato manual também foi baixa.

Como apresentado por Kunz, a escolha dos canais de publicação pode ter uma relação com o objetivo da publicação daqueles resultados de pesquisa pelo próprio 
pesquisador - que pode ser a divulgação e formação de alunos, a influência em pautas públicas, ou a inovação na área (a partir de uma nova forma de interpretação ou o levantamento de um dado ${ }^{36}$. Se considerarmos que, em geral, livros monográficos são mais voltados à preparação de alunos, como manuais, coletâneas agregam análises mais superficiais a temas novos e artigos se voltam para a comunidade científica, não é possível inferir isso dos dados que apresentamos. Pesquisas futuras podem complementar as análises neste sentido.

Sobre o público com o qual se dialoga, com base nos dados apresentados, identificamos que as publicações em idioma português e por meio de editoras ou revistas nacionais podem limitar a internacionalização das ideias e a integração no debate acadêmico internacional. Apesar de os pesquisadores se voltarem para temáticas internacionais, pudemos observar que há um baixo grau de internacionalização de suas produções.

Em temas específicos, a produção em geral tem se concentrado desproporcionalmente em questões de comércio e integração. A relação de temas de produção dialoga diretamente com os eixos temáticos - e sua proporção - também no espaço de ensino. Mas, essa relação não é direta com os grupos de pesquisa e financiamentos. Como observado na seção 1.C, há poucos grupos registrados e financiados, quais sejam: dois projetos em "comércio e investimento", um projeto em "contratos internacionais" (1 projeto) e dois projetos em "mercado de capitais e tributação". Sem fazer uma avaliação individual de cada grupo, mas apenas colocando-os em contexto nos eixos temáticos que prevalecem na produção, é curioso observar a relação entre a preponderância da temática "integração" e a ausência de grupos de pesquisa com este foco. Também não resulta proporcional em relação à produção em mercado de capitais e tributação e os resultados de pesquisa.

\section{Considerações finais}

O desafio a que nos propusemos neste artigo foi identificar o perfil do pesquisador em DIE e de sua produção nas áreas de ensino e pesquisa no âmbito

36 KUNZ, I. Dinâmica de produção de conbecimento na área de direito no Brasil. 2011. 245 f. Tese (Doutorado) - Programa de Pós-Graduação em Política Científica e Tecnológica, Instituto de Geociências, Universidade Estadual de Campinas, Campinas, 2011. p. 141 e ss. da academia brasileira, sem conjugar a isso uma leitura normativa sobre a concepção do campo do DIE. Em razão disso, o critério que direcionou este artigo foi a autodeclaração dos pesquisadores nos registros de suas atividades na Plataforma Lattes. No decorrer do artigo, as limitações impostas pelo uso desta base foram apontadas, o que já pode nos ajudar a trazer elementos para investigar outros instrumentos para o nosso reconhecimento do campo.

Nos diferentes exercícios a que nos propusemos neste texto, identificamos alguns traços marcantes de quem somos e o que fazemos. Trata-se de um campo com envolvimento crescente de organizações, pesquisadores e temas. Contudo, curiosamente, esse crescimento é, ainda, muito concentrado em algumas IES, em algumas pessoas e poucos temas. Ao fim do texto, fica a percepção de que ainda somos poucos e de esse exercício de mapeamento foi só um começo.

\section{ReferênCias Bibliográficas}

BARDIN, L. Análise de conteúdo. Tradução Luís Antero Reto, Augusto Pinheiro. São Paulo: Edições 70, 2011.

BERELSON, B. Graduate education in the United States. New York: McGraw-Hill, 1960.

BRAGA, M. M. S.; SANTOS, P. C. Formação acadêmica dos líderes de grupos de pesquisa em direito nas universidades públicas do Estado de São Paulo. In: OLEGÁRIO, Maria da Luz; RAMALHO, Antônio Germano; TASSIGNY, Monica Mota. (Org.). Direito, educação, ensino e metodologia jurídicos. Florianópolis: CONPEDI, 2014. v. 2. p. 455-473.

BRAGA, M. M. S.; VENTURINI, A. E. J. F. (Inter) disciplinaridade: a formação do corpo docente de um programa de pós-graduação em direito. In: GERALDO, Pedro Heitor Barros; FONTAINHA, Fernando de Castro; MEZZAROBA, Orides. (Org.). Direito, educação, ensino e metodologia jurídicos. Florianópolis: FUNJAB, 2012. p. 12-28.

BRAGA, M. M. S.; VENTURINI, A. E. J. F. Endogenia acadêmica em um programa de pós-graduação em direito. In: MEZZAROBA, Orides; TAVARES NETO, José Querino; VASCONCELOS, Silvia Andréia. (Org.). Direito, educação, ensino e metodologia jurídicos. Florianópolis: FUNJAB, 2013. p. 91-108. 
BRASIL. Conselho Nacional de Desenvolvimento Científico e Tecnológico. Tabela de Áreas do Conhecimento. Disponível em: <http://www.cnpq.br/documents/10157/186158/TabeladeAreasdoConhecimento.pdf>. Acesso em: 06 abr. 2016.

BRASIL. Coordenação de Aperfeiçoamento de Pessoal de Nível Superior. Documento de área 2013. Disponível em: < http://www.capes.gov.br/images/stories/download/avaliacaotrienal/Docs_de_area/Direito_doc_ area_e_comiss $\% \mathrm{C} 3 \%$ A3o_16out.pdf $>$. Acesso em: 14 set. 2015.

BRASIL. Coordenação de Aperfeiçoamento de Pessoal de Nível Superior. Relação de Cursos Recomendados e Reconhecidos 2015. Disponível em: <http://conteudoweb. capes.gov.br/conteudoweb/ProjetoRelacaoCursosServ let?acao $=$ pesquisarIes\&codigoArea $=60100001 \&$ descri caoArea $=\&$ descricaoAreaConhecimento $=$ DIREITO\& descricaoAreaAvaliacao=DIREITO $>$. Acesso em: 14 set. 2015.

BRASIL. Coordenação de Aperfeiçoamento de Pessoal de Nível Superior. Tabela de áreas do conbecimento. Disponível em: <http://www.capes.gov.br/images/ stories/download/avaliacao/TabelaAreasConhecimento_072012.doc >. Acesso em: 06 abr. 2016.

BRASIL. Ministério da Educação. Instituições de Educação Superior e Cursos Cadastrados, Sistema e-MEC. Disponível em: <http://emec.mec.gov.br/>. Acesso em: 14 set. 2015.

BRASIL. Ministério da Educação. Parecer CNE/CES n. 55, de 18 de fevereiro de 2004. Diretrizes Curriculares Nacionais para o curso de graduação em Direito. Disponível em: <http://portal.mec.gov.br/cne/arquivos/ pdf/2004/ces0055_2004.pdf>. Acesso em: 06 abr. 2016.

CARREAU, D.; FLORY, T.; JULLIARD, P. Droit internacional économique. Paris: Persée, 1990.

CHARNOVITZ, S. What is international economic law? Journal of International Economic Law, v. 14, n. 1, p. 3-22, 2014.

GHIRARDI, José Garcez (Coord.) et al. Introdução: quem é o professor de Direito no Brasil? Observatório do Ensino do Direito, São Paulo, v. 1, n. 1, p. 10-11, out. 2013. Disponível em: <http://direitosp.fgv.br/ sites/direitosp.fgv.br/files/arquivos/relatorio_oed_ out_2013quem_e_o_professor_de_direito_no_brasil. pdf>. Acesso em: 13 mar. 2016.
GIBBS, Graham; FRIESE, Susanne; MANGABEIRA, Wilma C. The use of new technology in qualitative research: introduction to issue 3(2) of FQS. Forum: Qualitative Social Research, v. 3, n, 2, May 2002. Available at: $<$ http://www.qualitative-research.net/index.php/fqs/ index >. Access on: 14 Sept. 2015.

HERDEGEN, M. Principles of international economic law. Oxford: Oxford University Press, 2013.

HORTA, H. Deepening our understanding of academic inbreeding effects on research information exchange and scientific output: new insights for academic based research. Higher Education, v. 65, n. 4, p. 487-510, Apr. 2013.

HUDEC, R. International economic law: the political theatre dimension. Journal of International Economic Law, v. 17, n. 1, p. 9-15, 1996.

JACKSON, J. H. International economic law: reflections on the "boilerroom" of international relations. Journal of International Law and Policy, v. 10, n. 2, p. 595606, 1994.

JOHNSON, J. B.; REYNOLDS, H. T.; MYCOFF, J. D. Political science research methods. 6th ed. Washington: CQ Press, 2008.

KONOPASEK, Z. Making thinking visible with Atlas. ti: computer assisted qualitative analysis as textual practice. Forum: Qualitative Social Research, v. 9, n. 2, May 2008. Available at: <http://www.qualitative-research. net/index.php/fqs/index>. Access on: 14 Sept. 2015.

KUNZ, I. Dinâmica de produção de conbecimento na área de direito no Brasil. 2011. 245 f. Tese (Doutorado) - Programa de Pós-Graduação em Política Científica e Tecnológica, Instituto de Geociências, Universidade Estadual de Campinas, Campinas, 2011.

ORTINO, F.; ORTINO, M. Law on the global economy: in a need for a new methodological approach? In: PICKET, C; BUNN, I; WARNER, D. International economic law: the state and future of the discipline. Oxford: Hart Publishing, 2008. p. 89-106.

PAUL, Joel R. The new movements in international economic law. American University Journal of International Law and Policy, v. 10, n. 2, p. 607-617, 1995.

PERRY-KESSARIS, A. (Ed.) Socio-legal approaches to international economic law: text, context, subtext. New York: Routledge, 2013. 
PETERSMANN, E. U. International economic theory and international economic law: on the tasks of a legal theory of international economic order. In: MAC DONALD, R.; JOHNSTON, D. The structure and process of international law: essays in legal philosophy, doctrine and theory. Leiden: Brill, 1986. p. 227-262.

QUIVY, R.; CAMPENHOUDT, L. V. Manual de investigação em ciências sociais. 6. ed. Lisboa: Gradiva Publicações, 2013.

REITZ, Curtis R. International economic law. Journal of International Economic Law, v. 17, n. 1, p. 29-32, 1994.

SCHWARZENBERGER, G. The principles and standards of international economic law. Brill: Leiden, 1966. (Col- lected Courses of the Hague Academy of International Law, v. 117).

TRACHTMAN, Joel P. The international economic law revolution. Journal of International Law, v. 17, n. 1, p. 3361, 1996.

VAGTS, Detlev F. International economic law and the American Journal of International Law. American Journal of International Law, v. 100, n. 4, p. 769-782, Oct. 2006.

ZAMORA, S. International economic law. Journal of International Economic Law, v. 17, p. 63-67, 1996. 
Para publicar na Revista de Direito Internacional, acesse o endereço eletrônico www.rdi.uniceub.br ou www.brazilianjournal.org.

Observe as normas de publicação, para facilitar e agilizar o trabalho de edição. 